\title{
Le rôle du Prophète dans l'approche marxiste de l'histoire de Bandalī Jawzī (1871-1942)
}

\author{
Min tārīkh al-ḥarakāt al-fikriyya fì l-islām (De l'histoire des mouvements \\ de pensée en islam)
}

Renaud Soler

Si j'avais d'abord accueilli son discours par un sourire d'incrédulité, bientôt me revint en mémoire le livre d'Antoni - une histoire de Russie - qui me parut se rouvrir devant moi. Le conte merveilleux que me chantait le vieux, je le suivais dans le livre, et, bien que tout y fût fidèle, le sens en était changé.

MAXIME GORKI, Confession (1908)

La Vie de Jésus, parue en 1864, comme les articles d'Ernest Renan (1823-72) consacrés à l'islam primitif, sont parsemés d'analogies entre les idées de Jésus ou de Muhammad, et les idéologies politiques du temps. Jésus « anarchiste», « communiste », à l'origine d'une « immense révolution sociale $»^{1}$; Muhammad facteur d'une «révolution profonde $»^{2}$, promoteur d'une « religion naturelle, libérale, sérieuse $»^{3}$ : simples analogies qui ne sont jamais justifiées, jamais explicitées et toujours lancées comme en passant. Dans les années 1880 et 189o, des orientalistes allemands commencèrent à développer des analyses plus précises sur la nature politique de l'islam, comme August Müller (1848-92), dans son histoire de l'Islam4, et Hubert Grimme (1864-1942), dans une biographie du Prophète où il attribuait explicitement à Muhammad des idées socialistes ${ }^{5}$. Ces allégations furent discutées et contestées par l'orientaliste néerlandais

1 Renan, Vie de Jésus, 196.

2 Renan, "Mahomet et les origines de l'islamisme", 267.

3 Renan, "Mahomet et les origines de l'islamisme", 285.

4 Müller, Der Islam im Morgen- und Abendland.

5 Grimme, Mohammed. 
Christiaan Snouck Hurgronje (1857-1936) ${ }^{6}$ mais attestent du moins d'une évolution importante par rapport à Renan: de vagues analogies ne suffisent plus ; des concepts tels que «communisme» sont dotés, au moins implicitement, d'une définition qui fonde la comparaison. Il n'est plus question de parler de communisme ou de socialisme du Prophète en simple considération de certaines tendances favorables à l'égalité, mais parce que les sources, envisagées selon les méthodes critiques de l'orientalisme, exhibent certains traits caractéristiques du concept, comme le régime de propriété de la terre, la fiscalité ou l'organisation du pouvoir politique. Si l'on ne peut guère qu'acquiescer à une analogie ou la refuser, il est en revanche possible d'assentir ou récuser un argument élaboré sur des références partagées. Dès le début du $\mathrm{XX}^{\mathrm{e}}$ siècle, les orientalistes suppléèrent cette approche purement intellectualiste par l'étude des forces, des groupes sociaux, qui déterminèrent l'émergence de l'islam et la carrière prophétique : ce furent, par exemple, les études du jésuite belge Henri Lammens (1862-1937) sur l'Arabie à la veille de l'islam ${ }^{7}$, ou les monumentales Annali dell' Istām du prince italien Leone Caetani (1869-1935)

À partir des années $195^{\circ}$ et 1960, une sociologie de l'islam fondée sur les catégories analytiques du marxisme commença d'être produite par des savants comme Montgomery Watt (1909-2006) ${ }^{9}$ ou Maxime Rodinson (1915-2004), jusqu'à embrasser le problème éminent de l'époque, la décolonisation et l'émergence du Tiers-Monde, c'est-à-dire d'une part penser les rapports entre libération nationale et révolution sociale, d'autre part les stratégies de développement à mettre en œuvre ${ }^{10}$. Dans le chemin qui conduisit de l'analogie mondaine de Renan à une approche sociologique de l'islam, un seuil majeur avait déjà été franchi par les orientalistes du début du siècle, qui ne se contentèrent pas d'attribuer à Muḥammad et à d'autres grands protagonistes de l'Islam certaines idées sociales, mais définirent les forces et les groupes sociaux susceptibles de les porter. Le passage de la comparaison anhistorique de concepts politiques, c'est-à-dire de l'histoire des idées, à l'histoire sociale, ou l'approche sociologique de l'islam, fut ainsi largement préparé par l'orientalisme savant. Ce fut ensuite, à partir des années 1920, en Union Soviétique, que des marxistes, qui eux-mêmes n'étaient souvent pas orientalistes, commencèrent de poser systématiquement, à partir des travaux de leurs devanciers

\footnotetext{
6 Snouck Hurgronje, "Une nouvelle biographie de Mohammed".

7 Lammens, Le Berceau de l'islam.

8 Caetani, Annali dell' Islām.

9 Watt, Muhammad at Mecca; Watt, Muhammad at Medina.

10 Rodinson, Islam et capitalisme; Rodinson, Marxisme et monde musulman. Voir surtout, dans ce dernier ouvrage, le texte de 1961, "Problématique de l'étude des rapports entre Islam et communisme", 130-80.
} 
bourgeois, le problème de la structure de classes de l'islam ${ }^{11}$. Les participants prirent et défendirent différentes positions afin de rendre compte de la place de l'islam dans l'histoire des formations économiques qui se succédèrent dans l'histoire de l'humanité, soit selon le schéma du passage du stade primitif au socialisme en passant par l'esclavagisme, le féodalisme et le capitalisme, soit selon celui d'un certain mode de production asiatique spécifique. La description acribique qu'en fait Michael Kemper permet de dégager deux éléments capitaux : les approches étaient généralement essentialistes - et contredisaient paradoxalement la conception marxiste de la religion comme superstructure, qui eût dû empêcher de considérer l'islam en soi comme l'idéologie de telle ou telle classe; de surcroît, une forte corrélation existait avec les enjeux politiques nationaux - la situation des minorités musulmanes soviétiques - et internationaux - les relations de l'Union Soviétique avec l'Orient et l'action de la III ${ }^{\mathrm{e}}$ Internationale, le Komintern, fondée en 1919 - qui finirent par étouffer complétement le débat au début des années 1930.

Nous aimerions adjoindre au concert de voix ressuscitées par Michael Kemper une autre voix à la fois marginale et centrale par ce qu'elle annonce, voix d'un palestinien chrétien orthodoxe rallié au marxisme, Bandalī Ṣalībā Jawzī, ou Panteleymon Krestovič Juze, installé en Russie puis en Azerbaïdjan et qui écrivit en arabe et en russe sur des sujets aussi divers que la philosophie islamique, l'histoire des chrétiens d'Orient, de l'islam et de l'Azerbaïdjan et la lexicographie arabe et turque. S'il s'inscrit en plein dans le débat soviétique des années 1920, son œuvre principale, rédigée en arabe mais préparée par des articles en russe, est profondément originale: sa lecture de l'islam n'a rien d'essentialiste, et son objet principal, une histoire du mouvement communiste en islam depuis l'époque du Prophète Muhammad dans ses dimensions économiques, sociales et politiques. Elle se présente comme une étude du dépérissement passé de la religion en islam, qui se lit tout aussi bien, croyons-nous, comme un plaidoyer pour un futur dépérissement.

\subsection{Bandalī Jawzī: une vie de la Palestine ottomane à l'Azerbaïdjan soviétique}

Bandalī Ṣalībā al-Jawzī naquit à Jérusalem en 1871 dans une famille orthodoxe qui pouvait se prévaloir d'une origine arabe ghassānide ${ }^{12}$. Il fut très jeune laissé

11 Kemper, "The Soviet Discourse"; Kemper, "Red Orientalism".

12 Abū Khalīl, Bandalī Jawzī. Il est la source de Sonn, Interpreting Islam, 3-11; Sonn, "Bandali al-Jawzi's Min Tarikh”. Tamara Sonn donne pourtant la date de naissance de 1872 ; nous 
orphelin par la mort de ses parents. Après sept années d'études primaires au couvent orthodoxe d'al-Mușallaba, à Jérusalem, il passa quatre ans au couvent de Kiftīn, modernisé sur le modèle des écoles missionnaires dans la seconde moitié du XIX ${ }^{\mathrm{e}}$ siècle, près de Tripoli du Liban, avant d'achever sa scolarité au séminaire de Nazareth, fondé en 1886 par la Société impériale orthodoxe de Palestine ${ }^{13}$. Le séminaire devait former les enseignants des écoles orthodoxes du Proche-Orient. À l'issue de leur scolarité, dispensée en russe et en arabe, les meilleurs d'entre eux étaient envoyés en Russie ${ }^{14}$. C'est ce qu'il advint avec Bandalī Jawzī qui fut envoyé d'abord au Séminaire de Vifanskaya (1889-92), près de Moscou, puis à l'Académie théologique de Moscou (1892-95) et, sur sa demande, à celle de Kazan (1895-96).

Il commença à y enseigner l'arabe à partir de 1896 , le français à partir de 1899. L'Académie théologique de Kazan avait été fondée en 1797 pour former les missionnaires destinés à travailler les musulmans de la Volga. En 1854, une division spéciale fut mise en place pour étudier et lutter plus efficacement contre l'islam, qui servit ensuite la politique de christianisation relancée par le tsar Alexandre II $(1855-81)^{15}$. Bandalī Jawzī soutint en 1899 une thèse consacrée au mu'tazilisme, qui divisa le corps enseignant en raison de sa mansuétude supposée envers l'islam. Ce serait la raison pour laquelle son avancement fut rapidement bloqué à l'Académie, et à partir de 1916, il commença d'enseigner le droit musulman à la Faculté de droit de l'université de Kazan. Il semble avoir continué son enseignement de l'arabe et du français à l'Académie théologique pendant toute cette période. Il exerça aussi, à partir de 1912 et pendant la Première Guerre mondiale, une fonction de censeur de presse $^{16}$.

Kazan était en ce temps un important centre économique et intellectuel. L'université avait été fondée en 1804, et jusqu'au transfert des études orientales à Saint-Pétersbourg en 1854, ce fut même le grand centre de l'orientalisme

préférons la date de Shawqī Abū Khalīl qui a rencontré la famille de Bandalī Jawzī. Les sources russes évoquent 1870 : cf. Kostrjukov et Habibullin, "Pantelejmon Krestovič Žuze"; Kostrjukov, Žuze Pantelejmon Krestovin. Kostrjukov donne la bibliographie des travaux en russe consacrés à Bandalī Jawzī, qui sont nombreux et commencèrent à être produits dès le début du $\mathrm{XX}^{\mathrm{e}}$ siècle, puis dans les années 1960-80 et enfin depuis la fin de l'Urss. La thèse elle-même porte surtout sur l'activité d'historien, d'orientaliste et de pédagogue de Bandalī Jawzī et ne s'intéresse guère à ses liens avec le marxisme et les mouvements nationaux des années 1920 .

13 Notice "Juze Panteleymon", qui évoque la période 1880-82. Or le séminaire fut fondé par la Société, elle-même fondée en 1882, en 1886 (d'après Stavrou, Russian Interest), ce qui pose un problème de chronologie.

14 Hopwood, Russian Presence, 143-46.

15 Werth, At the Margins of Orthodoxy, 177-99, et surtout 183-92.

16 Kostrjukov et Habibullin, "Pantelejmon Krestovič Žuze", 97. 
russe ${ }^{17}$. Au début du $\mathrm{xx}^{\mathrm{e}}$ siècle, les orientalistes qui demeuraient à Kazan étaient en relation avec les principaux courants de pensée représentés chez les Tatars musulmans. Le jadidisme, né dans le troisième quart du XIX ${ }^{\mathrm{e}}$ siècle sous l'égide du Tatar de Crimée Ismail Gasprinski (1851-1914) comme un mouvement de réforme du système éducatif musulman, défendait aussi l'émancipation de la femme, le progrès économique, le renforcement des liens entre les peuples turco-musulmans et la création d'une koinè turque ${ }^{18}$. La majorité des jadidis prônait plutôt la coopération avec l'Empire tsariste et la participation aux institutions, légitimait les études dans les écoles russes et le travail dans l'administration impériale ${ }^{19}$. Il s'agissait donc d'une forme de réformisme musulman comparable, et parfois en rapport, avec celui que l'on trouvait dans d'autres régions du monde musulman. À la suite de la révolution de 1905, ces jadidis se retrouvèrent dans le parti İttifāk ül-müsliminn, créé au moment des Congrès musulmans de 1905-1906, à l'initiative des musulmans de Kazan, pour grouper les musulmans de l'Empire. Des mouvements socialisants ou socialistes se développaient à la même époque, principalement à Kazan et à Bakou : une organisation fut créée par les Bolcheviks russes du parti social-démocrate à Kazan ; à Bakou, le parti Hümmet fut fondé en 1904 comme branche «nationale » du Parti social-démocrate russe, puis le parti Müsāvāt naquit en 1911 de la collaboration entre dirigeants du mouvement national et des socialistes ${ }^{20}$.

Les travaux préparés à cette époque par Bandalī Jawzī sont remarquables et le rapprochent indéniablement du jadidisme libéral. Sa première œuvre publiée à Kazan en 1898-99 est un manuel de russe pour les enfants arabes ${ }^{21}$. Après la publication de sa thèse, il livra en 1903 un dictionnaire arabe-russe en deux volumes, qui fut d'usage courant jusqu'au milieu du $\mathrm{Xx}^{\mathrm{e}}$ siècle en URSS $^{22}$. Ses travaux se partagent ensuite, jusqu'en 1917, entre des études sur l'histoire islamique: en 1903, une traduction de l'ouvrage de l'orientaliste hollandais Wilken sur le matriarcat chez les Arabes et un ouvrage sur le Prophète, Muhammad le Mecquois et Muhammad le Médinois, des recherches sur le Coran (1914); des études sur le christianisme oriental et l'histoire du Liban;

17 Sur les études orientales à l'université de Kazan au XIX ${ }^{\mathrm{e}}$ siècle, avant leur transfert à l'Université de Saint-Pétersbourg en 1854, Schimmelpennick van der Oye, "Imperial Roots". Concernant le $\mathrm{xx}^{\mathrm{e}}$ siècle, Usmanov, "The Struggle".

18 Lazzerini, "Ǧadidism". Ses racines plongent plus profondément dans l'histoire du $\mathrm{XVIII}^{\mathrm{e}}$ siècle, cf. Dudoignon, "Djadidisme, mirasisme, islamisme".

19 Baldauf, "Jadidism in Central Asia", 8o.

$20 \quad$ Bennigsen et Lermercier-Quelquejay, L'Islam en Union soviétique, 38-72.

21 Liste des publications in Abū Khalīl, Bandalī Jawzī, 136-42. Nous n'avons malheureusement pas pu mettre la main sur Muhammad le Mecquois et Muhammad le Médinois.

22 Notice Wikipédia, "Panteleymon Juze" ; Öner, "Kâşgarlı Mahmud". 
une réflexion sur Les Musulmans de Russie et leur avenir (1917). Ses articles se retrouvent aussi bien dans des revues russes que des revues arabes, dont les deux principales à les publier furent le Muqtațaf et la Majallat al-kulliyya de l'Université américaine de Beyrouth. Il aurait contribué à fonder, avec d'autres missionnaires de Kazan, la revue Mir Islama (Le Monde de l'islam) ${ }^{23}$. Bandalī Jawzī ne publiera plus de livres ni d'articles jusqu'en 1923; il semble toutefois avoir continué à enseigner et à étudier jusqu'à la soutenance d'un second doctorat en langue arabe en 1921.

Il vécut donc la Révolution de 1917 et la plus grande partie de la guerre civile (1917-21) à Kazan, qui fut l'un des centres majeurs de l'élaboration d'un communisme national adapté à l'islam et susceptible d'être exporté en Orient. Mulla-Nur Vahitov (1885-1918) et Mir Sultan Galiev (1880-1942 ?) jouèrent à partir de 1917 un rôle directeur dans ce mouvement. Les musulmans ralliés de diverses origines, nationalistes, anciens jadidis, pan-turcs et pan-islamistes, firent un temps cause commune avec les bolcheviks pendant la guerre civile; en même temps, Vahitov et Sultan Galiev entreprirent de jeter les bases d'un mouvement communiste autonome par rapport au bolchévisme russe autour de plusieurs idées-forces: nécessité d'une alliance plus ou moins durable avec la bourgeoisie nationale, inexistence d'un prolétariat tatar, rôle directeur des Tatars dans l'exportation de la révolution en Orient ${ }^{24}$. En dépit des promesses bolchéviques sur la création d'une République nationale musulmane en mars 1918, les institutions communistes musulmanes furent liquidées pendant l'année 1918. Le nouveau pouvoir put certes empêcher la fondation d'un grand État musulman et communiste autonome, mais l'afflux massif de musulmans dans le parti communiste russe reposa le problème de l'intérieur : les communistes nationaux jouèrent un rôle majeur dans la vie politique et culturelle des régions musulmanes jusqu'en 1923, et encore très important jusqu'aux grandes épurations des partis communistes nationaux à partir de $1928^{25}$.

L'Azerbaïdjan connut une évolution politique différente à partir de février 1917, qui conduisit à la proclamation de la République démocratique d'Azerbaïdjan en mai $1918^{26}$. Quand Bandalī Jawzī y arriva au début des années 1920,

23 Notice Wikipédia, "Panteleymon Juze". D’après Bennigsen et Lermercier-Quelquejay, Sultan Galiev, 62, Sultan Galiev y aurait collaboré avant la Première Guerre mondiale, à une époque où il écrivait beaucoup pour la presse.

24 Bennigsen et Lermercier-Quelquejay, Sultan Galiev, 93-94.

25 Bennigsen et Lermercier-Quelquejay, L'Islam en Union soviétique, 84-12o. Plus de détails dans leurs ouvrages : Les Mouvements nationaux et Sultan Galiev, ainsi que dans Bennigsen et Wimbush, Muslim National Communism.

26 Sur la spécificité de l'Azerbaïdjan, Georgeon, "Note sur le modernisme", mentionne la présence du chiisme, la présence d'une bourgeoisie nationale dominée et d'une puissante minorité arménienne, et l'essor de l'exploitation du pétrole de Bakou. 
invité à enseigner dans la nouvelle université fondée en 1919, l'Azerbaïdjan était déjà réoccupé par l'Armée rouge et avait été transformé en République socialiste soviétique depuis avril 1920. Toutefois, il faut noter que le projet d'université était plus ancien : il avait été évoqué dès le premier Congrès des musulmans du Caucause en avril 1917 et fait l'objet d'un accord entre toutes les tendances représentées ${ }^{27}$. Bandalī Jawzī aurait été invité à Bakou à l'époque de la République indépendante mais serait arrivé pendant les premiers mois de domination soviétique ${ }^{28}$. Il obtint un doctorat en langue arabe du département de philologie arabe en 1921, avant de devenir, entre 1922 et 1926, le premier doyen de la faculté indépendante d'études orientales (fermée en 1928). Il fut enfin nommé professeur en 1927. Pendant toute la décennie, il joua un rôle actif dans la vie intellectuelle à Bakou en participant notamment à l'organisation du célèbre congrès de turcologie de 1926, aux côtés de Vassili Bartol'd (1869-1930), le grand orientaliste russe d'origine allemande, et à la commission de réforme de l'alphabet cyrillique, pour l'adapter aux langues d'Asie centrale alors écrites en caractères persans ${ }^{29}$.

Selon Shawqī Abū Khalīl et Tamara Sonn, Bandalī Jawzī connut des problèmes de santé qui l'empêchèrent de travailler entre 1932 et 1937 ; il prit sa retraite en 1938 et mourut à Bakou en 1942. Cela est très improbable : la faculté d'études orientales avait été fermée en 1928 et les intellectuels azerbaïdjanais furent liquidés en quasi-totalité dans les années $193^{30}$. Son propre fils Vladimir Panteleymonovič, qui devint physicien en URSs, fut arrêté en $1937^{31}$. La notice Wikipédia en azéri consacrée à Bandalī Jawzī indique, en citant sa fille, qu'au retour d'un voyage d'études en Palestine et en Syrie en 1928, il avait été accusé par un certain Bukşin (l'historien et ethnographe Alexander Bukshpan), dans la revue Bakinskiyrabočiy (L'Ouvrier de Bakou), d'être un agent à la solde de l'impérialisme britannique. Il aurait été ensuite arrêté en février 1940, torturé, puis libéré en raison de son âge et sa santé, avant de mourir en $1942^{32}$.

27 Altstadt, The Azerbaijani Turks, 81; Swietochowski, Russian Azerbaijan, 148.

28 Notice Wikipédia, "Panteleymon Juze".

29 Sur le développement de l'historiographie azerbaïdjanaise, Türkoğlu, "1917 İhtilali'nden”. Nous n'avons pu consulter l'ouvrage d'Aziz Ubeydullin, important historien azerbaïdjanais des années 1920, publié à Bakou en 1930, 1oİl İçerisinde Azerbaycan'da Tarih Elminin Inkışafi.

30 Baberowski, Der Feind.

31 Kostrjukov et Habibullin, "Pantelejmon Krestovič Žuze", 96.

32 Kostrjukov et Habibullin, "Pantelejmon Krestovič Žuze”, 97, mentionnent bien l'arrestation de Bandalī Jawzī mais ne donnent pas de date précise. Comme le suggère Stefan Reichmuth, ce sont peut-être ses origines arabes qui protégèrent Bandalī Jawzī pendant une grande partie des années 1930 des persécutions du pouvoir stalinien contre les élites nationales des différentes républiques soviétiques de l'URss. 
La carrière de Bandalī Jawzī dans les années 1920 se comprend donc en rapport avec la politique soviétique des nationalités et ses relations avec l'islam: d'une part la politique soviétique de lutte contre l'islam, pragmatique entre 1921 et 1927 et de plus en plus affirmée à partir de 1928, consista d'abord à liquider les biens de mainmorte (waqf), abolir le droit coutumier et coranique et surtout fermer les écoles confessionnelles, puis à éliminer les dirigeants communistes musulmans et mener une propagande anti-religieuse ${ }^{33}$. D'autre part, la politique de contrôle de la vie intellectuelle nationale, que ce soit en Azerbaïdjan ou contre l'orientalisme «bourgeois $»^{34}$, se fit de plus en plus stricte. Sa production savante reprit en 1923, après les affres de la guerre civile, avec plusieurs articles publiés dans la revue azerbaïdjanaise Maarif va madaniyyat (Sciences et civilisation), intitulés « Du mouvement communiste en islam au IX ${ }^{\mathrm{e}}$ siècle » et consacrés au mouvement de Bābak. Shawqī Abū Khalīl y fait référence en évoquant un article de soixante-dix-neuf pages intitulé «De l'histoire du mouvement communiste en islam (Min țärīkh al-ḩaraka al-shuyūiyya fì l-islām) » et publié dans une revue scientifique (majallat ilmiyya). Larticle semble avoir été rédigé en russe; nous ne disposons pour le moment d'aucune preuve que Bandalī Jawzī écrivait en azéri, même si l'on sait par ailleurs qu'il connaissait le turc et étudiait des sources historiques en cette langue. Un autre article, «Discours sur la personnalité historique de la nation turque», porte sur la place des Turcs dans l'histoire. Si l'on ajoute les traductions d'extraits des historiens musulmans classiques consacrés à l'Azerbaïdjan, pour la plupart restées manuscrites, et une collaboration active, à partir de 1927, à l'Encyclopédie soviétique de l'Azerbaïdjan (1941), il appert que Bandalī Jawzī s'intéressa de plus en plus à l'histoire de son pays de résidence, et plus largement du Caucase, sans toutefois rien négliger de l'histoire de l'islam, du christianisme oriental et de l'époque contemporaine: l'ouvrage que nous allons étudier fut publié en 1928, suivi en 1933 d'une traduction en arabe de l'histoire des Ghassanides de Theodor Nöldeke (1836-1930), en collaboration avec Constantin Zurayq (1909-2000 $)^{35}$; on note aussi des articles sur l'impôt foncier et la capitation en islam (1931), une trilogie d'articles sur le faux prophète Musaylima, diverses

33 Bennigsen et Lermercier-Quelquejay, L'Islam en Union soviétique, 150-55; Bobrovnikov, "Contribution".

34 Rodionov, "Profiles under Pressure", 47-57, décrit la position de plus en plus précaire de Vasilii Bartol'd (1869-1930) et Ignatii Krachkovskii (1883-1951), et plus généralement de l'école de Saint-Pétersbourg/Léningrad, par rapport aux nouveaux orientalistes prolétariens de Moscou.

Nöldeke, Die ghassânischen Fürsten ; Jawzī et Zurayq, Umarā’ Ghassān. 
contributions de lexicographie arabe et turque ${ }^{36}$ et une analyse des relations anglo-égyptiennes (1930).

Ni son biographe palestinien, Shawqī Abū Khalīl, ni sa biographe occidentale, Tamara Sonn, ni la notice de Wikipédia en azéri ne sont très précis sur les affiliations intellectuelles de Bandalī Jawzī. Tamara Sonn a tendance à le rapprocher de Sultan Galiev ${ }^{37}$ alors que Shawqī Abū Khalīl tend à en faire un chrétien réformiste qui aurait toute sa vie maintenu des liens étroits avec la Palestine $^{38}$. Pour les rédacteurs de la notice en azéri, Bandalī Jawzī est l'un des pères fondateurs de la culture nationale de l'Azerbaïdjan. Ils n'ont pas complètement tort, mais aucun ne pose le problème dans toute sa largeur.

Bandalī Jāwzī maintint en effet des liens étroits avec la Palestine où il se rendit à plusieurs reprises au cours de sa vie, de même qu'en Égypte, en Syrie, en Irak et en Iran, commissionné par l'université de Kazan ou de Bakou pour acheter des manuscrits orientaux ${ }^{39}$; il fut très proche de la jeunesse nationaliste palestinienne du Club arabe (al-Muntadā l-'arabī), ralliée à Faysal pendant la Révolte arabe de 1916 et à l'époque du Royaume arabe de Damas (1920), et entretint sa vie durant une correspondance avec Khalīl al-Sakākīnī (18781953), fondateur de la Madrasa dustüriyya en 1909, l'une des premières écoles modernes de Palestine, Muhammad Is‘āf al-Nashāshībī (1885-1948) et Jamīl al-Khālidī (1876-1952) ${ }^{40}$. Pourtant dès 19oo, Bandalī Jawzī avait renoncé à rentrer s'installer à Jérusalem, comme en atteste une lettre de sa fille Anastasia adressée à son cousin Nașrī: alors que son père était rentré pour s'installer à Jérusalem en 1900, en dépit de son mal du pays, il n'avait pas pu supporter l'atmosphère pleine de calomnies et de servitude de la ville ${ }^{41}$. Il repartit donc à Kazan où il se maria; tous ses enfants portèrent par la suite des prénoms russes et firent des études supérieures en URss, la grande majorité en sciences exactes et jusqu'au niveau du doctorat, et y firent souche. Bandalī Jawzī lui-même écrivit toute sa vie en arabe et en russe ses ouvrages et articles scientifiques. Il porta toujours un intérêt profond à l'histoire du Proche-Orient et au

36 Bandalī Jawzī a en particulier écrit dans Maarif və mədəniyyat un article sur Kâşgarlı Mahmmūd (m. 1102/1105), l'auteur du célèbre Dìvān Lüghāt ül-türk. Cf. Öner, "Kâşgarlı Mahmud".

37 Sonn, Interpreting Islam, 15-22.

38 Abū Khalìl, BandalīJawzī, passim.

39 De manière générale, les orientalistes russes eurent de plus en plus de mal à voyager en Orient à partir des années 1920, le cas de Bandalī Jawzī est à cet égard original.

40 Abū Khalīl, Bandalī Jawzī, 109-27. Henry Laurens mentionne brièvement Bandalī Jawzī dans La Question de Palestine, 424-25, sous le nom fautif et mal vocalisé de Saliba al-Juzi.

41 Cité par Abū Khalīl, Bandalī Jawzī, 98, puis 102 : kāna ya'tazim an yabqā bayna ahli-hi wa-așdiqāihi, fa-qad balagha al-ḩanin bihi mablaghan shadìdan, walakinna wālidì, lāyastațī an ya īsha fí jaww malì bi-l-dasā’is wa-l-ubüdiyya. 
nationalisme arabe, mais il fut aussi, sans conteste, un Russe et un Soviétique assimilé, un Azerbaïdjanais d'adoption. En l'absence de renseignements biographiques plus précis et sans pouvoir pour le moment accéder à l'intégralité de son œuvre, c'est donc par le truchement de son magnum opus en arabe, Min tārīkh al-harakāt al-fikriyya fì l-islām ${ }^{42}$ (De l'histoire des mouvements de pensée en islam), que nous pouvons reconstruire plus précisément les rapports qu'entretenaient, dans les années 1920, Bandalī Jawzī avec les courants intellectuels et les interprétations de l'histoire de l'islam de son temps: le nationalisme arabe, les diverses formes de réformisme musulman, du jadidisme libéral aux courants socialisants, et les différentes interprétations marxistes de l'islam, des communismes nationaux à l'orientalisme soviétique.

\subsection{Une interprétation marxiste de l'histoire islamique}

Min tārīkh al-harakāt al-fikriyya fì l-islām fut publié à Jérusalem en août 1928 par l'imprimerie Bayt al-Maqdis, sous la supervision de Khalīl al-Sakākīnī. Trois cents exemplaires de l'ouvrage furent envoyés au Caire à Muhammad 'Alī al-Ṭāhir (1896-1974), le directeur palestinien de la revue al-Shūrā, lui aussi défenseur du nationalisme arabe ${ }^{43}$. Malgré les suspicions de certains intellectuels arabes, comme Muhammad Kurd 'Alī (1876-1953), devant les velléités de répandre le communisme qu'ils prêtaient, non sans raison, à l'auteur, l'ouvrage fut rapidement épuisé et reconnu comme une contribution importante à l'histoire de la pensée en islam ${ }^{44}$. La traductrice de l'ouvrage en anglais, Tamara Sonn, le considère comme la première interprétation marxiste de l'islam ${ }^{45}$ : l'ouvrage s'inscrivait en réalité dans le débat soviétique des années 1920 sur la nature de l'islam, il n'était donc pas isolé. Pour elle, Bandalī Jawzī décrit l'islam comme une «réforme sociale en faveur de la fin de l'oppression»; les Omeyyades puis les Abbassides subvertirent le message originel mais «l'esprit égalitariste de l'islam fut maintenu vivant dans divers mouvements de réformes au cours de l'histoire islamique ${ }^{46}$. Son objectif ultime aurait

42 Le mot $\min$ prend ici le même sens que le $z u$ allemand dans le titre de Nietzsche Zur Genealogie der Moral, qui indique la tentative, la démarche hypothétique sur la provenance, la logique et la valeur des valeurs.

43 Abū Khalīl, Bandalī Jawzī, 105.

44 Sonn, Interpreting Islam, 3-11.

45 Sonn, Interpreting Islam, 39-52 ; Sonn, "Bandali al-Jawzi's Min Tarikh".

46 Sonn, Interpreting Islam, 39: "Jawzi characterizes Islam as a social reform demanding the end of oppression. The exigencies of power politics under the dynastic caliphates, 
donc été d' «éveiller le monde musulman à la nature essentielle de l'islam » ${ }^{47}$ et d'établir la «justice sociale fondée sur l'essentielle égalité de tous les hommes devant Dieu ${ }^{48}$. Bandalī Jawzī se serait donc proposé de suivre «les progrès de cet objectif depuis sa genèse dans le cour du Prophète jusqu'au temps présent ${ }^{49}$ pour établir «la compatibilité des valeurs islamiques et socialistes $»^{50}$.

Cette interprétation est à revoir: Bandalī Jawzī exploite, dans Min tārīkh al-harakāt al-fikriyya fì l-islām, la méthode du matérialisme historique pour faire une histoire du communisme en islam, conçu comme un dépérissement de la religion islamique, au point de vue économique (l'évolution de la propriété de la terre, des activités commerciales), social (la position de la femme) et politique (l'organisation du pouvoir), depuis l'époque du Prophète jusqu'au mouvement des Qarmates dont l'histoire est prolongée jusqu'au xve siècle. L'objectif ultime est de prouver à ses lecteurs arabes que l'avenir du monde arabe passe par le nationalisme arabe (ou panarabisme) et le socialisme: si le monde arabe a été capable une première fois de sortir de la religion pour construire une préfiguration de la société socialiste chez les Qarmates, il en sera capable une seconde fois à la suite de l'URss. Il faut signaler encore que l'ouvrage fut surtout réédité dans les années 1970 et au début des années 1980, à l'apogée des mouvements progressistes au Moyen-Orient et juste avant le début de l'extension de l'empire du néolibéralisme autoritaire ${ }^{51}$. Lédition que nous utilisons est précédée d'une préface ${ }^{52}$ du grand intellectuel marxiste libanais Ḥusayn Muruwwa (1910-87), écrite trois ans après la publication en 1978 de son œuvre la plus célèbre, al-Naza'āt al-māddiyya $f \grave{\imath}$ l-falsafa al-'arabiyya wa-l-islämiyya (Les Tendances matérialistes dans la philosophie arabe et islamique). Bandalī Jawzī y est qualifié de pionnier et précurseur $(r \bar{a} i d)$ car il fut le premier, dans le monde arabe, à associer la méthode

according to his portrayal, vitiated and actually distorted that message, until it was virtually unrecognizable in any practical form. But Islam's egalitarian spirit was kept alive, Jawzi argues, in various reform movements throughtout Islamic history."

Sonn, "Bandali al-Jawzi's Min Tarikh", 89.

48 Sonn, "Bandali al-Jawzi's Min Tarikh", 9o.

49 Sonn, "Bandali al-Jawzi's Min Tarikh", go.

$50 \quad$ Sonn, "Bandali al-Jawzi's Min Tarikh", 104.

51 Voici les rééditions (cf. Abū Khalīl, BandalīJawzī, 136-42) : Damascus, s.e., 1972 ; Jerusalem, Manshūrāt Șalāḥ al-Dīn, 1977 ; Jerusalem, Ittiḥād al-Āmm li-l-Kuttāb wa-l-Ṣaḥafiyyīn al-Filisțīniyyīn, s.d. ; Beirut (?), Jam'iyyat al-Ṣadāqa al-Filisțīniyya al-Sufyātiyya, 1981 ; Dār al-Jalīl, 1982 ; Beirut, Dār al-Rawā’i', s.d.

Muruwwa, "Hākadhā naqra’ Bandalī Jāwzī". 
du matérialisme historique et l'étude du patrimoine arabo-musulman ${ }^{53}$. Il note aussi la prise de position (inhiya $\bar{a} z$ ) de l'auteur en faveur des Qarmates, comme mouvement intellectuel et social ${ }^{54}$, prise de position qui n'entache pas la qualité de la recherche car elle repose sur une argumentation solide et s'explique par l'historicité même de l'œuvre considérée, écrite à une époque où l'application du matérialisme historique à l'histoire de l'islam n'en était qu'à ses prodromes ${ }^{55}$. Pour Husayn Muruwwa, et l'histoire des rééditions tend à le confirmer, il ne faisait aucun doute que Bandalī Jawzī appliqua, bien qu'imparfaitement, le matérialisme historique à l'histoire de l'islam.

L'introduction sert à Bandalī Jawzī pour affirmer l'unicité des lois sociales $(\text { nawāmīs ijtimāiciyya })^{56}$. Il reconnaît aux historiens allemands de la fin du $\mathrm{XVIII}^{\mathrm{e}}$ et de la première moitié du XIX ${ }^{\mathrm{e}}$ siècle (Barthold Georg Niebuhr, Leopold von Ranke et Friedrich Christoph Schlosser sont allégués) le mérite d'avoir posé les principes de l'historiographie et des méthodes de la critique historique modernes, mais considère que ces historiens maljugèrent de l'histoire de l'Orient qu'ils ne connaissaient pas ou mal, et furent incapables d'y déceler une évolution (tațawwur) ou la réduisirent à un seul facteur ou une seule cause ${ }^{57}$. Il en est de même chez Renan qui se trompa dans ses textes sur l'islam et les sémites, comme le prouvent à l'évidence la vitalité des mouvements de pensée (haraka fikriyya) qui animent aujourd'hui le monde arabe. A contrario il se prévaut des vues de Bartol'd: les mêmes lois sociales valent pour l'Orient et pour l'Occident. Bandalī Jawzī en tire plusieurs conséquences importantes. D’abord, il faut écarter la religion comme cause du déclin du monde oriental ${ }^{58}$; ce sont l'immigration et les conquêtes par des peuples non civilisés (mutawahhisha) comme les Mongols et les Turcs, les croisades, l'essor de nouveaux centres de civilisation en Europe (marākiz al-ḥaḍāra al-jadīda) et le détournement conséquent des routes commerciales qui en sont les causes réelles, causes matérielles et non idéologiques, mais ce n'est pas tout : si les lois de l'évolution des sociétés sont les mêmes, cela signifie que les sociétés orientales passeront à l'avenir par les mêmes étapes historiques (marāhil, adwār

53 Muruwwa, "Hākadhā naqra' Bandalī Jāwzī", 1 : Lam yakun qad ittafaqa fi-hi [hādhā l-waqt] li-ậad min al-bāhithìn fì l-ālam al-'arabì an ya'qida mithl hādhā l-ṣila al-dirāsiyya bayna al-manhaj al-māddī al-tärīkhī wa-l-turāth al-'arabī-al-islāmī al-fikrì.

54 Muruwwa, "Hākadhā naqra' Bandalī Jāwzī", 2.

55 Muruwwa, "Hākadhā naqra’ Bandalī Jāwzī", 3-4. Kamā anna mujmal hādhihi l-zurūūf dhātahà lam takun li-takfì li-bāhith yashuqqu țarīqan bikran ilā mithl hādhā l-naw' min al-kitāba wifqa al-manhaj al-māddī al-tārīkhì (4).

$5^{6}$ Jawzī, Min tärīkh, 11-16/52-71. Nous citerons d'abord la version arabe puis la traduction.

57 Jawzī, Min tārīkh, 12-13/72.

$5^{8}$ Jawzī, Min tārīkh, 16/74: "Inhịịaaṭ al-'umrān fì l-bilād al-sharqiyya". 
ijtimāìyya) que les sociétés occidentales. Les mêmes mots répétés viennent parfaire la conclusion, de telle sorte que Min tārīkh al-ḥarakāt al-fikriyya fí l-islām offre un double miroir: d'un côté il montre comment, dans le passé, le monde musulman a pu sortir de la religion pour préfigurer une société socialiste, dont les germes furent perpétués dans les guildes, les confréries soufies, et transmis à l'Occident; de l'autre, il affirme avec confiance que, bientôt, l'Orient parcourra à nouveau, à l'instar de l'Occident, mais, comme nous le verrons, sans nécessairement passer par le stade du capitalisme, le chemin qui conduit à l'édification du socialisme. Il faut noter que des idées similaires, quoique moins élaborées, avaient été exprimées en 1923 par un couple de communistes tatars, Z. et D. Navshirvanov, dans un article de cinq pages intitulé «Les tendances communistes dans l'histoire de la civilisation musulmane» et publié dans Novyi Vostok ${ }^{59}$. Il y aurait un communisme primitif à l'époque du Prophète qui se serait épanoui dans le soufisme, chez les ismaéliens, dans la futuwwa anatolienne et dans les guildes de métiers. Les auteurs citent en particulier la révolte de Bedreddīn de Simavna contre les Ottomans en 141518: Bandalī Jawzī reprendra le même exemple en conclusion, dans un passage certainement inspiré par ses devanciers ${ }^{60}$. Pour les deux auteurs, la tâche des historiens n'est pas d'analyser l'histoire de l'Orient à l'aune des références à l'islam éparses chez Marx et Engels, mais de partir des méthodes marxistes pour montrer que l'Orient est sujet aux mêmes lois historiques que l'Occident. Les idées essentielles de l'introduction de Bandalī Jawzī sont là, quoiqu'une inflexion soit particulièrement nette : alors que les Navshirvanov considèrent que le communisme musulman s'exprima par excellence dans le soufisme turco-persan, Bandalī Jawzī entend montrer que ce sont les Arabes qui sont parvenus au stade du communisme en Islam, et expliquer précisément, à partir des sources historiques, comment l'islam y a dépéri.

Double miroir et double discours, donc : comme l'atteste la dédidace de l'ouvrage (non reproduite dans la version rééditée de 1981) à la «jeunesse arabe qui se réveille. À ceux qui ont libéré leurs esprits de l'influence des fausses croyances sociales, religieuses et nationales [ou nationalistes ?] ; à ceux dont l'entendement est sain et la conscience éveillée $»^{61}$, Bandalī Jawzī écrivait un

59 Kemper, “The Soviet Discourse”, 6-8.

6o Le poète communiste turc Nazım Hikmet écrira lui aussi, en 1936, un long poème consacré à Bedreddīn, intitulé Simavne Kadısı Oğlu Şeyh Bedreddin Destanı (Istanbul, Yeni Kitapçı, 1936). La figure de Bedreddīn paraît avoir joué, pour la gauche turque, un rôle stratégique analogue à celui du Prophète Muhammad dans le monde arabe.

61 Cité par Abū Khalīl, Bandalì Jawzì, 104: Ilā l-shabība al-'arabiyya al-nāhiḍa. Ilā lladhīna harrarū 'uqūla-hum min ta'thīr al-khurāfät al-ijtimāìyya wa-l-dīniyya wa-l-qawmiyya. Ilā aṣhāa al-'uqūl al-salīma wa-l-damāir al-hayya. Sonn, Interpreting Islam, 69, traduit: 
texte d'action en arabe, pour des Arabes et d'un point de vue panarabe, d'où la mention des fausses croyances nationales ou nationalistes. Mais en même temps, installé en URss, à la fin des années 1920 marquées par une vie intellectuelle foisonnante et théâtre de nombreux débats sur la nature de l'islam, il ne fait guère de doute qu'il faille aussi comprendre l'œuvre de Bandalī Jawzī dans ce cadre; de ce point de vue, Min tārīkh al-harakāt al-fikriyya fì l-islām est aussi un plaidoyer pour le communisme national, qui attestait du potentiel révolutionnaire de l'Orient musulman, du refus de tout essentialisation de l'islam et de la nécessité pour l'U Rss d'y organiser la résistance à l'impérialisme en soutenant les partis communistes et les mouvements nationaux. En ce sens, Bandalī Jawzī se rapprochait bien du sultangalievisme, bien que le rôle directeur du mouvement fût confié par lui aux Arabes et non aux Tatars.

Le premier chapire de l'ouvrage, intitulé usus al-islām al-iqtișādinya («les fondements économiques de l'islam» ${ }^{62}$ porte sur l'époque et sur la vie du Prophète; il s'inscrit à la fois dans les débats orientalistes issus du XIX ${ }^{\mathrm{e}}$ siècle, tels la sincérité de Muhammad ou la situation à La Mecque et Médine à la veille de la naissance de l'islam, et les débats des marxistes des années 1920 - qui n'étaient pas, pour la plupart, des orientalistes professionnels - sur la nature économique de l'islam. Pour Bandalī Jawzī, qui cite des orientalistes comme Julius Wellhausen (1844-1918), Leone Caetani (1869-1935), Henri Lammens (1862-1937), Nöldeke et Bartol'd, l'islam, plus qu'une idée religieuse, est un phénomène économique et social ; l'histoire de l'islam, par conséquent, s'explique par des raisons historiques, économiques, et non par le zèle religieux ou l'extrémisme (ta'așsub) des partis religieux ${ }^{63}$. Bandalī Jawzī commence par mettre en avant la compréhension intuitive de la situation socio-économique du Hedjaz par le Prophète, qui lui permet de faire avancer sa réforme religieuse.

Il prit conscience de l'origine du dynamisme économique et social qui se produisait, de son temps, à La Mecque, capitale du Hedjaz, et sut comment en profiter et l'employer à ses fins religieuses ou sociales élevées ${ }^{64}$.

"To the reawakening Arab youth; to those who are liberating their minds from the influence of irrational beliefs about social, religious, and national affairs; to those with healthyunderstanding and vibrant minds." Peut-être qu'about est de trop et introduit plus d'ambiguïté qu'il n'en lève. Le texte arabe est plus tranchant que la traduction anglaise, quoique non dépourvu de souplesse.

62 Jawzī, Min tärīkh, 17-53/75-91.

63 Jawzī, Min tārīkh, 17/75.

64 Jawzī, Min tārīkh, 18/75: Adraka mașdar al-ḥaraka al-iqtișādiyya wa-l-ijtimāìiyya al-latī zaharat fì ayyāmihi fì Makka 'așsimat al-Hijāz, wa-'arifa kayfa yastafìd minhāa wa-yusakhkhiruhā li-aghrādihi al-sāmiyya al-dīniyya kānat aw al-ijtimāìyya. 
Certains orientalistes attribuaient le succès de l'islam à la sécheresse et la pauvreté du milieu naturel qui poussèrent les Arabes à conquérir le monde (Caetani), ou plus généralement reconnaissaient que l'islam était un mouvement religieux qui réussit pour des raisons non religieuses (De Goeje). D'où la nécessité, pour Bandalī Jawzī, de mieux connaître le milieu et la société du Hedjaz à la veille de l'Hégire ; pour cela, l'information est empruntée à Henri Lammens ${ }^{65}$. La Mecque est décrite comme un grand centre commercial, avec peu d'activités agricoles et industrielles, et religieux, grâce au pèlerinage et la présence de la Kaaba, dominé par une élite très enrichie par ses activités commerciales excédentaires et la pratique de l'usure. La mention de l'usure est importante : Bandalījawzī en déduitla pratique, à grande échelle, de la condamnation coranique ( $Q 2: 276,286,24: 34)$ et la place au coeur de sa reconstruction de la structure de classes (tabaqa) binaire de La Mecque. Il fait fond sur l'étude de la terminologie coranique et des poètes préislamiques sensibles au désordre social, tout en intégrant des concepts marxistes contemporains ${ }^{66}$ : une élite dirigeante (le mala' de Q $38: 69$ ) de marchands, banquiers (așhāb al-bunūk) et gardiens de la Ka'ba domine et vit de l'exploitation de la masse des pauvres ( $a^{c} i z z a$ de Q 7), prolétaires (șacālīk) ${ }^{67}$, esclaves et hors-la-loi (ardhāl de Q 111). Il n'est pas anodin que cette structure sociale soit comparée par Bandalī Jawzì à celle de Byzance et celle de son propre temps. Dans le débat soviétique des années 1920, Bandalī Jawzī se rapproche des thèses de Reisner (1926) et de Beliaev (1930), des premiers travaux de Klimovitch (1927), qui voyaient dans l'islam un mouvement de petits marchands défavorisés, opposé à l'aristocratie commerçante, financière et religieuse de La Mecque ${ }^{68}$.

La mission de Muhammad a consisté en une réforme de cet ordre social injuste. Contrairement à ce que l'on peut lire chez des réformistes musulmans

65 Lammens, Le Berceau de l'islam.

66 Cf. Jawzī, Min tārīkh, 28/80: Alladhī yazhar min muțāla'at al-Qur'ān wa-imāàn al-nazar fì l-mufradāt al-musta'mala hunāk....

67 Selon Rodionov, "Profiles under Pressure", 47-48, c'est à Bandalī Jawzī (Panteleimon Dzhuze, uniquement qualifié ici de diplômé de l'académie théologique de Kazan) qu'est attribuée la traduction arabe de "prolétaire" par șu'lūk (pl. șa'ālīk), d'abord pour une banderole dans un congrès puis dans le slogan "Prolétaires de tous les pays, unissez-vous!", qui figurait sur les premiers billets soviétiques en 1919 (en russe, anglais, allemand, français, italien, anglais, chinois, arabe). L'auteur de l'article, très hostile au régime soviétique, y voit une visée ironique car pour lui, un șu lūk est rien moins qu'un brigand ; rien n'est moins sûr : un orientaliste comme Bandalī Jawzī savait que les șa'ālìk étaient des poètes-brigands de l'époque de la Gentilité, en marge du système tribal, parfois assimilés, depuis le $\mathrm{XIX}^{\mathrm{e}}$ siècle, à des proto-socialistes qui prenaient aux riches pour donner aux pauvres. Cf. Azari, "Șu'lūk".

68 Kemper, "The Soviet Discourse", passim. 
comme Rashīd Rị̣ā (1865-1935), voire même chez des libéraux comme Muhammad Ḥusayn Haykal (1888-1956), tous deux biographes du Prophète, ce n'est pas la corruption morale de la société mecquoise qui appelait un réformateur, mais les conditions sociales et économiques : «la structure sociale de La Mecque à la fin du vi ${ }^{\mathrm{e}}$ siècle prépara une place dans la société pour une personne qui serait dotée de la force et des qualités nécessaires ${ }^{69}$, comme la sensibilité, la gentillesse, l'intelligence, le sens politique, l'abnégation, la conscience de l'intérêt général et la connaissance du milieu mecquois. La vie du Prophète s'analyse donc selon deux facteurs déterminants : la formation (mansha') et le milieu (wasat). Muhammad fut un pauvre orphelin: le Coran lui rappelle que la pauvreté est la source même de sa force ( $Q$ 44:2-5) et Bandalī Jawzī fait du niveau de richesse la condition première de la réceptivité à la nouvelle religion. Son activité commerciale au service de la riche veuve Khadīja, qui devint ensuite sa femme, fut l'école de la pratique où il put découvrir la situation sociale de La Mecque, y réfléchir et l'analyser, et chercher des remèdes à ses maux ${ }^{70}$.

Bandalī Jawzī réfute d'une part les historiens européens qui prétendaient que le Prophète était un capitaliste qui défendait les intérêts des riches, d'autre part ceux qui, à l'instar d'Hubert Grimme, faisaient de lui un socialiste ou un communiste. La solution qu'il offre est la suivante :

[Muhammad] se mit du côté des pauvres et des prolétaires opprimés avec un grand courage, défendit ouvertement leurs intérêts vitaux en s'exposant au danger, indifférent aux conséquences de ses actes, poussé à cela par des facteurs moraux et religieux, plus qu'économiques ou financiers ${ }^{71}$.

Muḥammad est un authentique réformateur mais un réformateur inconscient: à lui-même, les causes sociales disparaissent, voilées par les motivations religieuses (muhtajiba bi-hijāb min al-dìn al-kathîf $)^{72}$. Voilà la ruse de l'histoire à l'origine de l'islam, et une solution matérialiste au vieux débat orientaliste sur la sincérité du Prophète. Aussi Bandalī Jawzī voit-il, sous l'opposition manifeste

69 Jawzī, Min tārīkh, 30/81: Al-nizāàm al-ijtimā̄i fì Makka a'adda fì awākhir al-'aṣr al-sādis mahallan ïjtimāìyyan li-shakhṣ tawāfarat fìhi al-qiwāa aw al-șifāt al-lāzima.

$70 \quad$ Jawzī, Min tārīkh, $3^{2} / 81$.

71 Jawzī, Min tārīkh, 36/83: Innahu waqafa fì jānib al-fuqarā’ wa-l-șa'ālīk al-mažlūmìn waqfata rajul mughāmir fì l-hayāt, wa-dāfa'ajahāran 'an mașālihihim al-hayawiyya mu'arrị̂an nafsahu li-l-khațar wa-ghayr mubālin bi-'awāqib 'amalihi madfüan ilā dhālika bi-'awāmil adabiyya wa-dīniyya akthar minhu bi-'awāmil iqtișādiyya aw māliyya.

72 Jawzì, Min tārīkh, 36/83. 
entre infidèles et croyants, une opposition réelle, économique, entre riches et pauvres: la prédication mecquoise a pour thème principal la confrontation des riches, les riches oncles du Prophète lui-même, Abū Lahab et Mughīra (Q 113 :1-3), et les riches Quraysh qui craignaient de voir leurs positions économiques et religieuses dominantes menacées ( $Q$ $36: 38$ et $22: 6$ ), et la compassion pour les pauvres ( $\mathrm{Q} 26: 14-22)$. Le problème de l'infidélité et de la conversion à l'islam naquit donc d'une divergence de points de vue sur les réformes nécessaires pour régler les problèmes économiques et sociaux de La Mecque.

L'hostilité de plus en plus violente des Quraysh conduisit à l'Hégire: Muhammad devint alors un chef politique (sayyid, zaìm, ra'šs mamlaka $\left.w \bar{a} s i^{i} a\right)^{73}$ doté du pouvoir de mener des réformes importantes : la destruction des liens claniques de la Gentilité ('aṣabiyyat al-jāhiliyya), la réalisation des valeurs d'amour, d'égalité et de fraternité, l'amélioration de la condition des pauvres grâce à l'aumône légale, ainsi que d'autres mesures sociales (sharāa $\tau^{\tau}$ ijtimā iyya) en faveur des femmes, des esclaves, contre l'infanticide et l'usure ${ }^{74}$. Mais cela ne fait pas de Muhammad un socialiste : l'aumône légale, la zakāt, est une mesure de réduction des écarts de richesse, écrit-il, et non de suppression, comme dans les régimes socialistes aujourd'hui. Plus généralement, Muhammad conduisit des réformes dont on trouve des analogues à Rome ou à Byzance, sans s'attaquer aux causes des maladies de la sociétée ${ }^{75}$, comme le font les socialistes :

De ce point de vue, il n'y a rien d'incomparable avec les prophètes qui l'ont précédé, plus particulièrement les prophètes d'Israël : il préféra user d'expédients moraux - sauf en de rares occasions - plutôt que de recourir aux mêmes méthodes que certains réformateurs et hommes politiques européens, comme Lénine, chef du communisme russe, ou Mussolini et d'autres ${ }^{76}$.

Le Prophète est donc un prophète, qui croyait réellement agir sur commande de Dieu pour instaurer son ordre sur terre. Nul ne saurait lui faire le grief de ne pas avoir atteint, au VII ${ }^{\mathrm{e}}$ siècle, le même niveau de conscience historique que les socialistes du $\mathrm{Xx}^{\mathrm{e}}$ siècle. La fin du chapitre est consacrée à réfuter plus particulièrement la thèse selon laquelle Muhammad avait l'intention d'abolir

73 Jawzī, Min tārīkh, 41/86.

74 Jawzī, Min tārīkh, 42/86. Sonn traduit de manière erronée 'așabiyyat al-jāhiliyya par "ignorant fanaticism".

75 Jawzī, Min tārīkh, 42/86: Li-tuqtal kullu jarāthìm al-amrāẹ al-ijtimāàìya.

76 Jawzī, Min tārīkh, 44/87. 
la propriété privée des terres : pour Bandalī Jawzī, le système tribal arabe suffisait à empêcher la constitution de grands domaines entre les mains d'un seul homme, et la rente foncière était très faible; il n'y avait donc pas à La Mecque de classe paysanne exploitée par de grands propriétaires terriens, aussi le Prophète ne pensa-t-il pas à abolir la propriété privée ${ }^{77}$. Lorsqu'il fut à Médine, il trouva bien une population de paysans pauvres, sans aristocratie marchande et financière pour l'opprimer, ce qui explique le changement de langage et d'attitude du Prophète dans le Coran, mais les événements politiques conduisirent le Prophète à se montrer conciliant et à passer, au nom de l'amour de ses contribules et d'intérêts bien compris, des compromis (tasāhul mutabā$d a l)$ avec les Quraysh. Le traité de Ḥudaybiyya (Q 9:6o) inaugure le ralliement massif des Quraysh à l'islam, non pour des raisons religieuses mais politiques et socio-économiques ${ }^{78}$. L'islam en tant que force politique naquit donc d'un compromis entre Muhammad et l'habile chef de la république mecquoise (ra'īs jumhūriyyat Makka al-khabìr al-muḥannak), Abū Sufyān : au Prophète est reconnue la souveraineté spirituelle et temporelle, les obligations religieuses de la $z a k a \bar{t}$ et de la prière, l'abandon des idoles sont acceptés; en échange, La Mecque reste le centre religieux du nouveau pouvoir politique (mamlaka, jumhūriyya rūhiyya jadīda), les Quraysh sont intégrés à l'administration et le commerce demeure libre ${ }^{79}$.

L'histoire de l'islam va se poursuivre dans les deux directions frayées à l'époque du Prophète: le message religieux réformiste de Muhammad à La Mecque est développé par divers groupes sociaux qui le transforment par étapes en véritable doctrine communiste consciente, affranchie de toute dimension religieuse ; quant à la politique médinoise de Muhammad, poursuivie et parachevée par les dynasties califales, elle conduit à l'oubli rapide de la dimension sociale de l'islam et au renforcement de l'aristocratie fortunée, commerçante et financière, qui avait été, à l'époque mecquoise, la plus vivement combattue. Peut-être était-ce déjà la thèse principale de l'œuvre de jeunesse de Bandalī Jawzī, Muḥammad le Mecquois et Muḥammad le Médinois.

77 Jawzī, Min tārīkh, 46-48/88-9o. D’après Kemper, "The Soviet Discourse", 25-28, Tomara, professeur à l'Université des travailleurs de l'Orient, défendit en 1930 la théorie selon laquelle la base de classe de l'islam était formée des pauvres urbains, paysans appauvris et soumis aux paysans riches qui pratiquaient l'usure, et en concurrence pour les terres avec les nomades. Il interprétait l'apostasie à la suite de la mort du Prophète (ridda) comme la tentative des Bédouins de récupérer les terres distribuées par le Prophète aux paysans pauvres.

78 Jawzī, Min tärīkh, 49/89.

79 Jawzī, Min tārīkh, 52/9o. 
Dès l'époque des conquêtes, la question sociale passe au second plan; en même temps, les conditions économiques et sociales déterminent l'apparition de mouvements socialistes et communistes ${ }^{80}$. À l'époque du calife 'Uthmān (644-56) puis à l'époque omeyyade, le système administratif et fiscal est dévoyé au service del'enrichissement de l'élite arabe, qui constitue de surcroît de grands domaines avec les terres conquises en Égypte et en Irak qu'elle fait exploiter par des paysans pauvres et des esclaves noirs : une classe paysanne exploitée se constitue. Par ailleurs, le calife 'Umar (634-44), qui décide de maintenir l'impôt foncier (kharāj) sur les terres des convertis, suscite, en lien avec la shu'übiyya iranienne, évoquée d'après Ignaz Goldziher (1850-1921), la première opposition nationale au régime califal. Les Abbassides conduisent la même politique économique et financière que les Omeyyades mais réintégrent l'élite persane, supprimant ainsi son potentiel de révolte, tout en continuant à opprimer la classe paysanne et les anciens propriétaires et religieux zoroastriens. Tous les premiers soulèvements contre le régime sont expliqués par le recours à des causes économiques et sociales, là encore voilées par des motivations conscientes d'ordre religieux: « cette coloration [religieuse] n'était rien d'autre qu'un voile léger qui dissimulait des facteurs politiques et économiques, qui sont la raison réelle de ces révoltes ${ }^{81}$. Quant aux changements de politique militaire et coloniale, ils conduisent à la militarisation du pouvoir et à la féodalisation de l'Empire à l'époque abbasside. Dans le débat soviétique, l'islam primitif en vint à être considéré lui-même comme essentiellement féodal autour de 19311932, en lien avec la clôture du débat sur le mode de production asiatique et l'appesantissement de la chappe de plomb du stalinisme : la position officielle niait désormais l'existence d'une formation économique spécifique à l'Orient, considéré comme relevant tout uniment du féodalisme, et l'islam devint par conséquent - sans aucune preuve tirée de l'étude des sources - l'idéologie des « seigneurs féodaux» de La Mecque ${ }^{82}$. Bandalī Jawzī est évidemment loin de cette projection rétrospective de la situation abbasside sur l'islam primitif, mais n'en considère pas moins que l'émergence du communisme en islam se produit avec la féodalisation de l'Empire sous les Abbassides, c'est-à-dire sans passer par le stade du capitalisme.

8o Jawzī, Min tārīkh, 54-77/92-102. Sonn traduit fautivement le titre du chapitre par "Arab Imperialism and the Vanquished Nation". En arabe, al-imbarātūriyya al-arabiyya wa-l-umam al-maghlūba signifie en fait "L'Empire arabe et les nations vaincues" ; impérialisme se traduit par imbiryāliyya.

81 Jawzī, Min tārīkh, 74/101: Hādhihi al-ṣabgha lam takun illā hijāäban shaffāfan yahjub mā warāahu min al-'awāmil al-siyāsiyya wa-l-iqtișādiyya allatī hiya al-sabab al-haquīqū li-hādhihi al-thawrāt.

82 Kemper, "The Soviet Discourse", 34-40. 
Les trois chapitres suivants décrivent trois mouvements intellectuels en islam dans lesquels le référent religieux est dominant, puis instrumentalisé consciemment, enfin dépassé : c'est la révolte de Bābak et ses idées socialistes (tacalìmuhu al-ishtirākiyya), l'ismaélisme et le mouvement qarmate. Rien n'illustre mieux la subtile polysémie du discours de Bandalī Jawzī que le chapitre consacré au mouvement de Bābak. Il naît à la fin du viıI ${ }^{\mathrm{e}}$ siècle en Azerbaïdjan abbasside comme conséquence (natīja) du féodalisme, hérité de l'Empire sassanide et issu de la militarisation de l'Empire. Il faut noter qu'à la même époque, Bandalī Jawzī commençait à travailler plus précisément sur les sources de l'histoire de l'Azerbaïdjan à cette période, à les traduire en russe et à écrire sur la capitation et l'impôt foncier en islam ${ }^{83}$. Cela explique, selon lui, les comparaisons des historiens musulmans avec le mouvement de Mazdak au VI ${ }^{\mathrm{e}}$ siècle : non seulement les deux révoltes sont déterminées par les mêmes conditions économiques et sociales, comparables au Moyen Âge européen et à la Russie jusqu'à l'abolition du servage en 1861, mais attestent de surcroît la transmission des idées socialistes de Mazdak dans la classe paysanne exploitée, indifféremment avant et après la conquête musulmane, puis dans tous les mouvements révolutionnaires de l'islam ${ }^{84}$. Il est intéressant de noter que Bandalī Jawzī reconnaissait parfaitement le potentiel révolutionnaire des campagnes. Le mouvement de Bābak remettait en cause non pas l'islam, la domination arabe ou l'appartenance à la communauté des croyants, mais l'ordre social injuste qui opprimait les classes inférieures à l'intérieur de toutes les communautés de l'Empire. Bābak voulait une société sans classes, sans oppression, sans pauvres ni riches, régie par la justice, la fraternité et l'égalité : c'est la raison pour laquelle Bandalī Jawzī le qualifie de socialiste. Les deux mesures principales, connues seulement d'après des sources adverses proches des milieux califaux, dont l'information provient de la classique Geschichte der Chalifen (1848-51) de Gustav Weil (1808-89), auraient été la redistribution des terres, mais sans abolition de la propriété privée, et la libération des femmes ${ }^{85}$. On se souvient que Bandalī Jawzī avait traduit en arabe, en 19o3, Le Matriarcat chez les Arabes, de l'orientaliste hollandais Wilken, rejoignant par là maints penseurs chrétiens et musulmans d'Orient qui virent dans la condition faite à la femme une des causes majeures du retard de l'Orient. L'échec du mouvement est attribué à des divisions internes mais surtout à l'incapacité, pour ce mouvement iranien, de s'ouvrir franchement aux populations turques et arabes ${ }^{86}$.

83 Abū Khalīl, Bandalī Jawzī, $136-42$.

84 Jawzī, Min tārīkh, 95/110.

85 Jawzī, Min tārīkh, 90-91/108-9.

86 Jawzī, Min tārīkh, 116/119-2o. 
En résumé, Bābak représente la première étape réformiste et nationaliste sur la voie du communisme, dont la base sociale est l'alliance de la paysannerie et des propriétaires zoroastriens exclus du pouvoir.

On se souvient aussi que Bandalī Jawzī avait publié en 1923-1924 dans Maarif va madaniyyat plusieurs articles sous le titre «De l'histoire du mouvement communiste en islam au IX ${ }^{\mathrm{e}}$ siècle », consacrés au mouvement de Bābak. Or l'écrivain azerbaïdjanais Cəfər Cabbarlı (1899-1934), proche du parti nationaliste Müsavāt, qui avait étudié à la Faculté orientale de l'université de Bakou entre 1924 et 1927 avec Bandalī Jawzī, s'empara de Bābak pour en faire un symbole national dans sa tragédie Od galini (La Mariée de feu, 1928), qui chante la résistance du peuple azerbaïdjanais athée à la conquête musulmane, mais qui fut aussi interprétée comme une critique de la domination soviétique ${ }^{87}$. Il serait intéressant de comparer les articles de 1923-24 avec le chapitre de Min tärïkh al-harakāt al-fikriyya fíl-islām : dans ce dernier ouvrage, Bābak est décrit comme le chef d'un mouvement avant tout persan et religieux, simple étape dans un procès historique beaucoup plus large de dépérissement de la religion. Bandalī Jawzī avait par ailleurs considéré les invasions turques et mongoles comme l'une des principales causes du déclin de la civilisation musulmane. Lorsqu'il écrivait pour un public azerbaïdjanais, Bābak, singularisé, pouvait en revanche devenir l'ancrage d'un communisme national, autant que d'une résistance nationale au bolchévisme russe.

Dans la logique de L'Histoire des mouvements de pensée en islam, les ismaéliens permettent de franchir une étape supplémentaire dans le dépérissement de l'islam grâce à l'invention d'une organisation adaptée, qui évoque le parti léniniste : pour Bandalī Jawzī, les ismaéliens avaient un véritable programme politique et social qu'ils faisaient passer consciemment pour un programme religieux; seulement aux degrés supérieurs de l'initiation dans l'organisation découvrait-on sa vraie nature. Autrement dit, les ismaéliens découvrent, pour la première fois, la forme du parti d'avant-garde et l'islam comme idéologie mobilisatrice pour les masses. Les grands principes du mouvement s'opposent terme à terme aux piliers du pouvoir abbasside, l'islam sunnite, la solidarité tribale et le nationalisme chauvin, en mettant en avant des droits égaux pour tous les peuples de l'Empire et une religion rationnelle, sans révélation, intégrée dans un système néoplatonicien ${ }^{88}$. Les buts politiques conscients sont d'abord similaires à ceux des chiites : donner le pouvoir aux Alides. Bandalī

\footnotetext{
87 L'orientaliste soviétique Tamara publia en 1936 à Moscou un ouvrage en russe sur Bābak, que nous n'avons pas pu consulter. Il existe aussi un film éponyme en azéri d'Eldar Quliyev sur Bābak, sorti en 1979. 
Jawzī prolongera ses réflexions sur le mahdisme quelques années plus tard ${ }^{89}$. Ils deviennent ensuite l'égalité entre les sexes et l'abolition de la propriété privée de la terre, préalable à sa redistribution gratuite. Deux caractéristiques singularisent les ismaéliens par rapport aux mouvements de type Bābak qui les ont précédés. D’abord les fondements scientifiques de leur doctrine :

La différence entre ceux-là [les partis communistes avant l'apparition de l'ismaélisme] et les communistes [les ismaéliens], c'est que les ismaéliens firent reposer leurs revendications sur des principes philosophiques scientifiques et non sur de purs principes moraux, comme le firent les communistes qui les précédèrent ${ }^{90}$.

Ensuite l'internationalisme, écrit en français dans le texte et traduit par $i k h \bar{a}^{\text {' }}$ haqīqū, comparé à l'universalisme de l'islam ou du catholicisme. L'internationalisme ismaélien repose sur les exigences de la raison (mațālib al-'aql al-salìm) et constitue le premier véritable dépassement du nationalisme en islam, en opposition avec la shưübiyya iranienne chauvine (en français dans le texte, traduit par 'așabiyya qawmiyya). Il paraît évident que Bandalī Jawzī, à l'unisson des communistes nationaux, prend ici position contre la monopolisation croissante du pouvoir par les bolcheviks russes, et contre la transformation de l'Orient en simple théâtre de la lutte de l'Urss contre ses ennemis capitalistes, manifestée par les conclusions, déjà en retrait par rapport à lépoque de la guerre civile, du Congrès de Bakou en juillet $1920^{91}$ et la ligne pour le moins fluctuante, au gré des intérêts de Moscou, du Komintern ${ }^{92}$. L'utilisation du terme «chauvinisme » fait référence aux Thèses d'avril (1917) de Lénine mais aussi à Sultan Galiev qui avait fustigé le «chauvinisme grand-russe», lequel, selon lui, ne faisait que parer des nouveaux atours de la dictature du prolétariat le vieux populisme russe du XIX ${ }^{\mathrm{e}}$ siècle ; il y opposait le concept de nation prolétaire et revendiquait pour les Tatars un rôle directeur dans l'exportation

89 Notons qu'il publie en juin-juillet 1933 dans le Muqtataf, vol. 83, $\mathrm{n}^{\circ}{ }_{1-2}$, deux articles intitulés "al-Sufyānī", qui portent sur ce phénomène.

$90 \quad J a w z \overline{1}$, Min tārīkh, 144/132: Al-farq bayna häulä' [al-ahzāb al-shuyūiyya qabla zuhūr

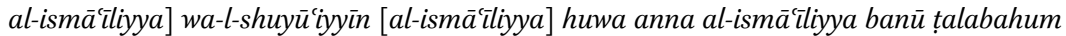
hādhā 'alā mabādi' falsafiyya 'ilmiyya lā 'alā mabādi' adabiyya maḥ̣̂a kamā fáal man sabiqahum min al-shuyūiyya. La conservation du terme "communistes" suggère peut-être que ce passage provient directement des articles sur le mouvement communiste en islam écrits par Bandalī Jawzī en 1923-24.

91 Cf. les transcriptions des discussions dans Riddell, To See the Dawn; voir aussi Premier congrès des peuples de l'Orient. Bakou 1920. Nous ignorons si Bandalī Jawzī assista au congrès de Bakou, où il se trouvait depuis le printemps de la même année.

92 Carrère d'Encausse et Schram, Le Marxisme et l'Asie (1853-1964). 
de la révolution en Orient ${ }^{93}$. Bandalī Jawzī opère un nouveau décentrement du monde russo-tatar vers le monde arabe ${ }^{94}$ : pour lui, ce sont les Arabes qui devaient se révolutionner eux-mêmes. Cela le conduisit non pas à revenir à un Prophète idéalisé, mais au contraire, à l'instaurer comme moment inaugural de l'histoire du communisme en islam, encore réformiste et non conscient de lui-même. En résumé, l'ismaélisme invente une organisation adaptée et des revendications vraiment communistes qui reposent sur une doctrine rationaliste et une stratégie internationaliste. Sa base sociale réside dans les nationalités opprimées par les Abbassides, mobilisées par l'avant-garde ismaélienne, grâce au chiisme. Son influence perdura dans la vie intellectuelle chez les «Frères de la sincérité », dans la philosophie et le soufisme, ou encore chez le poète sceptique al-Ma'arrī (m. 449/1057), mais le califat abbaside orthodoxe fut sauvé par les Turcs puis par le déclenchement des croisades.

Le rôle décisif dans le dépérissement de l'islam et sur la voie du communisme en islam fut assumé par les Qarmates de Bahreïn sous la conduite d'Abū Sa īid al-Jannābī (m. 913/14), qui appela à abandonner la plupart des principes et lois de l'islam pour fonder une république communiste, reposant sur la fraternité entre toutes les races et les religions et le bonheur sur terre, et non plus dans l'au-delà. Le mouvement fut rallié par les citadins, qui ne bénéficiaient pas du système abbasside, et par les bédouins qui abhorraient l'islam et ses pesanteurs. Historiquement, les Qarmates sont associés au chiisme imamite puis ismaélien, mais conquirent progressivement leur autonomie (istiqlāl dākhilī) qui leur permit de fonder un système républicain ou consultatif ( jumhūrī, shūrī) où les chefs étaient seulement les primi inter pares, uns parmi les membres du conseil (majlis idārī, 'aqdāniyya) ${ }^{95}$. Cette fois-ci, les comparaisons historiques ne portent plus sur le moyen âge occidental ou la Russie d'avant 1861, mais sur les républiques (populistes) d'Amérique latine et sur l'URSs : le gouvernement de Bahreïn fonctionne comme un soviet (șüfiyit) présidé par le fondateur de la République, puis par ses descendants et ses proches collaborateurs. Les Qarmates avaient atteint le même stade que la Russie de la Révolution d'Octobre. L'insistance sur la nature républicaine et consultative du

93 Bennigsen et Lemercier-Quelquejay, Sultan Galiev, 191-210; Renault, "Lidée du communisme musulman".

94 L'orientation arabe se lit aussi dans la préface de la traduction de l'histoire des Ghassanides de Nöldeke, où les deux traducteurs justifient le choix de l'œuvre par la nécessité de donner un modèle de bonne pratique historiographique aux historiens arabes, et d'éclairer une époque obscure de leur histoire commune. Sur l'historiographie proche-orientale de cette époque, Freitag, Geschichtsschreibung in Syrien 1920-199o; et Havemann, Geschichte und Geschichtsschreibung. 
pouvoir de Bahreïn, le rejet de l'hypothèse oligarchique (comme pour tous les concepts politiques, le mot est en français et traduit par hukūmat al-aqalliyya al-mustabidda) malgré la constitution d'une élite dirigeante autour de la famille Jannābī, ne sont certainement pas étrangers aux vicissitudes de la succession de Lénine, mort en 1924, et à la monopolisation du pouvoir par Staline.

Les mesures économiques sont clairement communistes, même si Bandalī Jawzī reconnaît que l'information historique insuffisante ne permet pas d'être assuré de l'abolition de la propriété privée de la terre : ainsi en va-t-il notamment de l'imposition d'un monopole d'État sur le commerce extérieur. Les taxes foncières sont abolies, les impôts frappant les fermiers et cultivateurs diminués et compensés par des taxes sur le commerce et le pèlerinage aux Lieux Saints.

L'existence de la République arabe socialiste à Bahreïn pendant toutes ces années, la préservation de son système original, son rayonnement pendant plus de cinq siècles et le succès économique signalé précédemment, en dépit des difficultés et des nombreux ennemis qui l'environnaient et aspiraient à la détruire et à écraser sa révolution, il n’y a pas de plus grande preuve que ladite République n'était pas seulement construite sur des fondements économiques et sociaux puissants, mais aussi sur des bases morales assurées et des principes éthiques véritables, comme le montre également la vie du groupe et des individus ${ }^{96}$.

Il était nécessaire de réfuter les accusations classiques d'hérésie et de débauche morale dont les historiens musulmans accablaient traditionnellement les Qarmates - et dont, parallèlement, les capitalistes occidentaux usaient sans vergogne contre les mouvements socialistes. Sous la description de Bahreïn transparaît l'Urss des années 1920: lorsque Bandalī Jawzī décrit comment, lorsque Abū Ṭāhir al-Jannābī (m. 944) se rapprocha des Abbassides, après qu'il eut rompu l'ancienne allégeance aux imposteurs Fatimides, il nie qu'il s'eût agi d'une trahison car, le cas échéant, écrit-il, le gouvernement soviétique, qui avait conclut des traités commerciaux avec certaines nations occidentales

96 Jawzī, Min tārīkh, 200-201/158: Inna qiyām al-jumhūriyya al-arabiyya al-ishtirākiyya fi l-Bahrayn kulla hādhihi al-sinīn al-țiwāl wa-hifžs nizāmihä l-gharīb wa-ta'thïrihi akthar min khamsat ajyāl thumma bulūghahā dhālika al-najāh al-iqtiṣādī alladhī asharnā ilāyhi sābiqan wa-dhālika ma'a mā kāna yuhịt bihā min al-șu'ūbāt wa-ta'addud al-khuṣūm al-mutashawwiqīn ilā hậ̣mihā wa-l-istīlà' 'alā tharwatihā, la-akbaru dalìl 'ala anna al-jumhūriyya al-madhkūra kānat qā̄ima laysa faqaț 'alā da'ā'im iqtișādiyya wa-jtimā'iyya qawiyya bal 'alā usus adabiyya qawìma wa-mabādi' akhlāqiyya șaḥịha kānat tatajallā fì hayāt al-majmü' wa-l-afrād 'alā $l$-sawä'. 
(l'Angleterre en mars 1921, l'Allemagne par le traité de Rapallo en avril 1922), serait lui-même en état de trahison envers la révolution, ce qui est bien sûr inconcevable ${ }^{97}$.

Après la sincérité du Prophète et l'utilisation consciente de la religion comme idéologie par les Ismaéliens, les Qarmates communistes représentent l'étape de la sortie de la religion ${ }^{98}$. De l'histoire des mouvements de pensée en islam est bien une histoire du dépérissement progressif de l'islam dans des mouvements authentiquement révolutionnaires. Les communistes russes et nationaux eux-mêmes s'étaient posé cette question, dont la réponse la plus fameuse est l'article de Sultan Galiev, publié en 1921, «Méthodes de propagande anti-religieuse parmi les musulmans $»^{99}$. Le bolchevik tatar y mettait l'accent sur la spécificité de l'islam (une religion récente, avec davantage d'éléments sociaux et politiques quéthiques et religieux, dont la législation contenait beaucoup de prescriptions positives) et la nécessité de définir des méthodes de propagande adaptées pour la combattre. Il s'agissait d'aborder, de manière générale, le problème avec «prudence et esprit pratique», pour se bien démarquer des méthodes des missionnaires orthodoxes actifs avant $1917^{100}$; plus spécifiquement, à chaque peuple devait correspondre une approche adaptée à son niveau économique, social et culturel : ainsi les Tatars sont les plus mûrs pour une propagande anti-religieuse fructueuse, alors que, dans le Turkestan beaucoup plus arriéré, « la campagne anti-religieuse ne peut être menée qu'avec des méthodes employées entre 1905 et 1910 par les jadids dans la région de la Volga »101. Les communistes sont donc justifiés d'exprimer leur propagande anti-religieuse soit dans un langage clair, soit, de manière dissimulée, dans un langage réformiste musulman. Bandalī Jawzī montre de même que les Qarmates usèrent parfois de termes religieux mais qu'en réalité,

97 Jawzī, Min tārīkh, 203-5/159-6o. Bandalī Jawzī se défausse apparemment de toute critique contre l'Unss, mais a contrario, ne pourrait-on pas y voir une critique implicite de la succession de Lénine ? Comme 'Ubayd Allāh fut l'Imam du temps, auquel les Qarmates firent allégeance, Lénine fut le meneur de la grande Révolution d'Octobre alors que son successeur, Staline, est vu comme un imposteur.

98 Jawzī, Min tārīkh, 207/261.

99 Traduit par Bennigsen et Lermercier-Quelquejay, Les Mouvements nationaux chez les musulmans de Russie, 226-38.

100 Sultan Galiev, "Les méthodes de propagande anti-religieuse parmi les musulmans", 229.

101 Sultan Galiev, "Les méthodes de propagande anti-religieuse parmi les musulmans", 237. Sur la propagande anti-religieuse soviétique à partir de la fin des années 1920 et jusqu’au milieu des années 1980, Bobrovnikov, "Contribution". Le recours aux travaux des missionnaires orthodoxes d'avant 1917 et des orientalistes dits "bourgeois", quoique violemment critiqués, associés aux lieux communs de l'athéisme militant de l'entre-deux-guerres puis de la seconde moitié du $\mathrm{xx}^{\mathrm{e}}$ siècle, est noté par l'auteur. 
ils ne croyaient en aucune religion positive ni principes extérieurs. Leurs idées relevaient d'une pensée ( $f i k r)$ politique et philosophique rationaliste mais pas d'une croyance religieuse ('aqìda) ${ }^{102}$.

Les Qarmates, en tant qu'Arabes d'un côté, ismaéliens d'un autre côté, étaient encore plus éloignés de la religion et de ses prescriptions extérieures que les communistes de ce temps, puisque leur vraie religion était leur grande revendication sociale, qu'ils vénéraient, et qu'ils croyaient, à la vie et à la mort, en la nécessité de la mettre en application ${ }^{103}$.

Bandalī Jawzī appliqua lui-même ces méthodes subtiles de propagande : voilà pourquoi le «mouvement communiste en islam» des articles de 1923-24, destinés à un lectorat plus avancé sur la voie du communisme, s'est changé en al-harakāt al-fikriyya fi l-islām («mouvements de pensée en islam») dans l'ouvrage en arabe, qui font écho aux mouvements de pensée qui animent le monde arabe contemporain. On peut imaginer que dans un contexte « arriéré », Bandalī Jawzī eût pu faire usage de la figure du Prophète pour amener les musulmans vers le communisme; mais lorsqu'il s'agit d'écrire de l'histoire, il n'hésite pas, en revanche, à lui rendre sa place véritable d'homme de foi qui agissait comme messager de Dieu, inconscient de l'autonomie des finalités sociales qu'il poursuivait. D'autres changements subtils se glissent dans le texte arabe : par exemple, les conquêtes arabes ne sont pas appelées fatḥ (pl. futūhn), littéralement «ouverture» (à l'islam), mais ihtilāl, occupation ${ }^{104}$. Les termes choquants, athéisme (ilhād) ou matérialisme (māddiyya) ne sont jamais écrits mais toujours suggérés par des périphrases: ainsi les Qarmates sont-ils des « adorateurs de la raison ('ibādat al-'aql al-salīm) » plutôt que des athées ${ }^{105}$, et les causes réelles des événements, offusquées par un «voile» (hijāb), comme Dieu dans le Coran $(Q 42,51)$ et dans la riche imagerie de la poésie spirituelle de l'islam ${ }^{106}$. Tout un jeu de correspondances, enfin, permet au lecteur d'envisager la reprise du mouvement communiste en islam: l'époque du Prophète

\footnotetext{
102 Jawzī, Min tärīkh, 207-9/161-62.

103 Jawzī, Min tārīkh, 207/161: Al-qarāmița, ka-a'rāb min jiha wa-ismāiéliyya min jiha ukhrā,

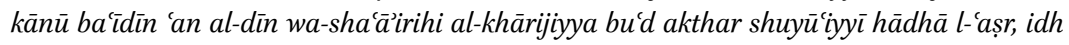
anna dìnahum al-ḥaqīqī huwa mațlabuhum al-kabìr al-ijtimāì alladhì kānū ya'budūnahu wa-yu'minūn bi-wujūb taḥqüqihi ìmānan qawiyyan yahyawna li-ajlihi wa-yamūtūn 'alayhi.

104 Cela n’a pas échappé à Abū Khalīl, Bandalī Jawzī, 223. Ihtitlāl est utilisé en turc pour traduire "révolution". Bandalī Jawzī, installé en Azerbaïdjan, avait très certainement ce sens à l'esprit en l'écrivant.

105 Jawzī, Min tärīkh, 208/162.

106 Jawzī, Min tārīkh, 36/83, 74/101. Peut-être même que la transcription de "soviet" avec l'emphatique, șūfiyit et non sūfiyit, comme cela s'est imposé au $\mathrm{xx}^{\mathrm{e}}$ siècle, visait-elle à susciter une association d'idées avec le soufisme? On se souvient que les époux Navshirvanov
} 
correspond à l'état de Byzance et de Rome (stade esclavagiste); l'époque abbasside au moyen âge occidental et à la Russie avant 1861 (stade féodal); les Qarmates de Bahreïn aux républiques populistes d'Amérique latine et surtout à l'Urss (stade communiste). À l'instar de Sultan Galiev, Bandalī Jawzī considérait vraisemblablement que le monde oriental pourrait passer directement du féodalisme au communisme en faisant l'économie du stade capitaliste.

L'intérêt de Bandalī Jawzī pour les Qarmates vient sans doute de la conjonction dans ce mouvement d'une dimension authentiquement socialiste et d'une dimension authentiquement arabe : le socialisme achevé des Qarmates préfigurait la grande Révolution de 1917 et démontrait aux communistes que le monde arabe allait connaître à l'avenir une nouvelle révolution socialiste ; son arabité démontrait aux moyen-orientaux que le socialisme était profondément ancré dans leur identité arabe, et qu'il était, lui et non une quelconque religion réformée, la clef de la lutte anti-coloniale et du développement économique. De l'histoire des mouvements de pensée en islam peut donc se lire à la fois comme un plaidoyer pour une meilleure prise en compte du monde arabe dans la vision du monde soviétique, et comme une contribution à l'érection d'un socialisme panarabe dont la vocation était clairement de devenir athée, quand la solidarité des peuples arabes socialistes se serait substituée à la solidarité de la umma où les chrétiens, comme lui-même l'était, demeuraient dans une position ambiguë de subordination.

Le régime des Qarmates de Bahreïn perdura jusqu'au $\mathrm{XV}^{\mathrm{e}}$ siècle, malgré des difficultés à partir de la fin du $\mathrm{x}^{\mathrm{e}}$ siècle ; Bandalī Jawzī considère que le monde musulman entra en déclin quand l'Occident commença sa renaissance, pour les raisons matérielles évoquées supra, contrairement à beaucoup d'orientalistes, et d'intellectuels moyen-orientaux à leur remorque, qui faisaient soit du $\mathrm{X}^{\mathrm{e}}$ siècle, soit du XII ${ }^{\mathrm{e}}$ ou du XIII ${ }^{\mathrm{e}}$ siècle (confrontation entre Ghazālī et Averroès conçue comme la défaite de la raison en terre d'islam, chute de Bagdad devant les Mongols en 1258), le début du déclin de l'islam. Quant à Bandalī Jawzīi, il tente de montrer en conclusion que, si les Ismaéliens et les Qarmates échouèrent à réaliser le programme socialiste, à cause de leurs divisions internes, des pouvoirs turcs et mongols et des croisades, son esprit a d'une part survécu dans les guildes de métiers (akhiler, eșnāf) et les confréries soufies, en particulier dans l'espace turco-persan, d'autre part été transmis à l'Occident chez les Templiers et dans les guildes professionnelles, chez les franc-maçons ou les jésuites ${ }^{107}$. Cette partie du raisonnement est la moins justifiée par un recours aux sources historiques : vraisemblablement à la suite des

avaient mis en avant, dans leur article de 1923, la proximité du communisme avec certains mouvements de révolte soufis. 
Navshirvanov, il n'allègue guère que la révolte soufie de Bedreddīn en Anatolie, en 1415-18, et le babisme de la Perse du XIX ${ }^{\mathrm{e}}$ siècle, qui devint ensuite réactionnaire en s'alliant avec les propriétaires terriens lors de la Révolution constitutionnelle; pourtant cette double translation est nécessaire pour respecter les présupposés de la démonstration de Bandalī Jawzī, que les nations orientales ont donné naissance à un authentique mouvement communiste sans passer par l'étape du capitalisme, et qu'à l'avenir, les Arabes sont, parmi les Orientaux, les mieux à même de conduire les nations de l'Orient vers le socialisme; entre les deux, il y a le transfert de l'idée communiste d'Orient vers l'Occident. Ce faisant, Bandalī Jawzī achève son histoire de l'islam comme moment historique dans l'invention du communisme: l'islam comme religion assumée par le Prophète et certains mouvements de révolte, comme celui de Bābak, tournée consciemment en idéologie mobilisatrice par une avant-garde ismaélienne, puis dépassée dans une organisation politique et économique authentiquement socialiste par les Qarmates, caractérisé par un gouvernement républicain et consultatif, la propriété collective de la terre, le monopole sur le commerce extérieur et l'égalité des conditions, en particulier entre les deux sexes. Plus qu'un livre sur le communisme de l'islam, De l'histoire des mouvements de pensée en islam est donc un ouvrage à deux fronts sur le communisme en islam, sur l'islam comme étape de l'histoire universelle qui conduit au dépérissement de la religion et à la diffusion mondiale du communisme : l'un regardait vers la Russie, l'autre était tourné vers le Moyen-Orient exploité par l'impérialisme occidental, stade suprême du capitalisme dans la théorie léniniste, et visait sa libération par un socialisme panarabe qui avait de surcroît à conquérir l'hégémonie culturelle face à l'islam, plutôt que de rechercher avec lui des accommodements et des compromis.

\section{7·3 Quel rôle joue donc le Prophète dans Min tārīkh al-ḥarakāt al-fikriyya fì l-islām?}

Pour Bandalī Jawzī, Muḥammad est un personnage historique qui joue un rôle majeur dans l'inauguration du mouvement communiste en Islam. Au lieu de s'interroger sur la sincérité du Prophète, selon les termes du débat orientaliste du XIX ${ }^{\mathrm{e}}$ siècle, et de chercher à faire le départ entre ce qui relèverait d'une authenthique œuvre religieuse et ce qui serait à inscrire au compte d'ambitions politiques, Bandalī Jawzī pose le problème de la mission prophétique dans des termes inspirés par le matérialisme historique, qui rendaient caduque le vieux débat. La carrière prophétique est incompréhensible si l'on considère qu'il était sincère dans son œuvre religieuse, insincère dans sa reconstruction de l'ordre 
social et politique, notamment à partir de l'époque médinoise. Muhammad fut un prophète stricto sensu, un homme convaincu d'agir selon les directives qu'il recevait de Dieu et qui concernaient aussi bien la réforme religieuse que la reconstruction d'une société plus juste. Cette distinction même du religieux et du politique est purement analytique, car le Prophète concevait toute la réalité au prisme de l'islam (ou, comme le dit Bandalī Jawzī, « sous un épais voile de religion»). De ce point de vue, la conception de Muhammad chez Bandalī Jawzī est un truisme : le Prophète était un prophète, en ce sens qu'il se considérait et agissait comme un prophète. Cette banalité méritait pourtant d'être rappelée contre des orientalistes qui avaient eu tendance à attribuer de manière anachronique à Muhammad des idées politiques et économiques d'un autre temps.

À partir de cette mise au point sur la vie du Prophète, Bandalī Jawzī l'intègre dans son schéma marxiste de l'histoire, qui analyse selon les principes du matérialisme dialectique. Le Prophète ainsi considéré est un réformateur, qui tenta de réduire les inégalités de richesse et l'oppression des femmes, de lutter contre le tribalisme, sans pour autant s'attaquer aux causes profondes des désordres sociaux. Bandalī Jawzī réfute particulièrement que le Prophète aurait eu l'intention d'abolir la propriété privée : au nom de la diffusion de l'islam, le Prophète passa un compromis avec les Quraysh, ce qui montre bien, par ailleurs, que ses conceptions de la réforme économique et sociale étaient assujetties à ses conceptions religieuses. Muhammad laisse donc un double héritage à sa communauté : Muḥammad le Médinois, son message réformiste ; Muhammad le Mecquois, son compromis politique avec les Quraysh. L'histoire de l'islam se poursuivra ensuite dans le jeu dialectique de ces deux legs : les mouvements marginaux, décrits comme hérétiques par l'hérésiographie proche du pouvoir califal, approfondiront le legs réformiste, qui les conduira à faire advenir par étapes un véritable communisme athée dans l'islam; les califats omeyyade puis abbasside feront du compromis politique une compromission permanente, qui conduira à renier la dimension sociale de l'islam pour mieux servir les intérêts de l'élite dominante. Dans chacun des deux mouvements, une partie de la mission prophétique est approfondie et portée par étapes à son accomplissement.

Au-delà de l'analyse marxiste que Bandalī Jawzī procure de la vie du Prophète Muhammad et de son héritage dans l'histoire de l'Islam, De l'histoire des mouvements de pensée en islam porte aussi trace d'une réflexion sur l'exemplarité et l'utilité du modèle prophétique dans la perspective de la lutte pour l'avènement du communisme. À l'instar de Sultan Galiev dans son article «Méthodes de propagande anti-religieuse parmi les musulmans», Bandalī Jawzī était convaincu de la nécessité d'employer un langage adapté à son interlocuteur 
ou son lecteur, pour le conduire progressivement au communisme. Comme il avait fallu plusieurs siècles pour passer du réformisme prophétique au communisme conscient des Qarmates, il fallait prendre le temps d'amener progressivement les musulmans à accepter la vérité du communisme, et, de surcroît, son athéisme. Cela explique le changement de titre entre les articles en russe de 1923, qui mentionnait le «mouvement communiste en islam », et le livre en arabe de 1928, qui n'indiquait plus que « les mouvements de pensée en islam », mais aussi maints choix sémantiques de Bandalī Jawzī dans le corps de son texte. Cette nécessaire adaptation du langage offre aussi la possibilité d'une autre lecture de l'ouvrage, non plus seulement comme une histoire linéaire, écrite d'un point de vue marxiste, du dépérissement de la religion en Islam, mais aussi comme un plaidoyer polyphonique en faveur de l'avènement du communisme, dont chaque chapitre serait adapté à un niveau de compréhension différent, depuis le musulman réformiste jusqu'au communiste athée. Le risque consistait alors à oublier que les premiers chapitres nétaient que les prodromes des suivants et à les extraire de la marche de l'histoire. De l'histoire des mouvements de pensée en islam était écrit selon une perspective marxiste, et donc évolutionniste ; sans cette perspective, il devenait très facile d'abstraire le Prophète de l'histoire et d'en faire un idéal indépassable, au lieu de lui restituer sa double dimension de figure du passé et de modèle dépassé pour certains, à dépasser pour d'autres.

\section{Remerciements}

Tous mes remerciements à Laurent Pugnot-Lambert, qui a accepté de me lire quelques travaux récents, en russe, consacrés à Bandalī Jawzī, et aux deux éditeurs de ce volume, Rachida Chih et Stefan Reichmuth, pour leurs remarques sur la première version de mon texte.

\section{Bibliography}

\section{Primary Sources}

Abū Khalīl, Sh. Bandalī Jawzī. 'Așruhu - Hayātuhu - Āthāruhu, Beirut/Damascus, Dār al-Fikr al-Mu'āșir/Dār al-Fikr, 1993.

Caetani, L. Annali dell' Islām, vol. 1, Milan, Ulrico Hoepli, 1905.

Jawzī, B. Min tārīkh al-harakāt al-fikriyya fì l-islām, Jerusalem, Mațba'at Bayt al-Maqdis;

s. l., Jam'iyyat al-Ṣadāqa al-Filisținniyya al-Sufyātiyya, 1981.

Jawzī, B., et Q. Zurayq. Umarä’’ Ghassān, Beirut, Imprimerie Catholique, 1933. 
Le Premier congrès des peuples de l'Orient, Bakou 1920: L'Internationale Communiste et la libération de l'Orient, Saint Petersburg, Éditions de l'Internationale communiste, 1921.

Muruwwa, Ḥ. "Hākadhā naqra’ Bandalī Jāwzī”, preface to B. Jawzī, Min tārīkh al-harakāt al-fikriyya fì l-islām, Jerusalem, Mațba'at Bayt al-Maqdis ; s. l., Jamiiyyat al-Ṣadāqa al-Filisținiyya al-Sufyātiyya, 1981, 1-10.

Renan, E. "Mahomet et les origines de l'islamisme", in Études d'histoire religieuse, Paris, Michel Lévy, 1857, 217-99.

Renan, E. Vie de Jésus, Paris, Gallimard, coll. Folio Classiques, 1974.

\section{Secondary Literature}

Altstadt, A. The Azerbaijani Turks: Power and Identity under Russian Rule, Stanford, Hoover Institution Press, 1992.

Azari, A. "Șu'lūk", in P. Bearman et al., eds. The Encyclopaedia of Islam, Second Edition, Leiden, Brill, 1960-2009, IX. Accessed 1 February 2021.

Baberowski, J. Der Feind ist überall. Stalinismus im Kaukasus, Munich, Deutsche Verlags-Anstalt, 2003 .

Baldauf, I. "Jadidism in Central Asia within Reformism and Modernism in the Muslim World", Die Welt des islams 41/1 (2001), 72-88.

Bennigsen, A., et C. Lermercier-Quelquejay. Les Mouvements nationaux chez les musulmans de Russie. Le "sultangalievisme" au Tatarstan, Paris, Mouton \& Co, 196o.

Bennigsen, A, et C. Lermercier-Quelquejay, L'Islam en Union soviétique, Paris, Payot, 1968.

Bennigsen, A., et. C. Lermercier-Quelquejay. Sultan Galiev. Le père de la révolution tiers-mondiste, Paris, Fayard, coll. "Les inconnus de l'histoire”, 1986.

Bennigsen, A., et S. E. Wimbush. Muslim National Communism in the Soviet Union: A Revolutionary Strategy for the Colonial World, Chicago, The University of Chicago Press, 1979.

Bobrovnikov, V. "The Contribution of Oriental Scholarship to the Soviet Anti-Islamic Discourse: From the Militant Godless to the Knowledge Society", in S. Conermann et. M. Kemper, eds, The Heritage of Soviet Oriental Studies, London/New York, Routledge, 2011, 66-85.

Carrère d'Encausse, H., et. S. Schram. Le Marxisme et l'Asie (1853-1964), Paris, Armand Colin, coll. "U”, 1965.

Conermann, S., et. M. Kemper, eds. The Heritage of Soviet Oriental Studies, London/ New York, Routledge, 2011.

Dudoignon, S. "Djadidisme, mirasisme, islamisme", in "Le réformisme musulman en Asie centrale", Cahiers du monde russe et musulman 37/1-2 (1996), 13-40.

Freitag, U. Geschichtsschreibung in Syrien 1920-1990. Zwischen Wissenschaft und Ideologie, Hamburg, Deutsches Orient-Instituts, 1991. 
Georgeon, F. "Note sur le modernisme en Azerbaïdjan au tournant du siècle", in "Le réformisme musulman en Asie centrale", Cahiers du monde russe et musulman 37/1-2 (1996), 97-106.

Grimme, H. Mohammed, 2 vols, Münster, Aschendorff, 1892-95.

Havemann, A. Geschichte und Geschichtsschreibung im Libanon des 19. und 20. Jahrhunderts, Beirut, Orient-Institut der Deutschen Morgenländischen Gesellschaft, 2002.

Hopwood, D. The Russian Presence in Syria and Palestine 1843-1914, Oxford, Clarendon Press, 1969 .

Kemper, M. "The Soviet Discourse on the Origin and Class Character of Islam, 19231933", Die Welt des Islams 49/1 (2009), 1-48.

Kemper, M. "Red Orientalism : Mikhail Pavlovich and Marxist Oriental Studies in Early Soviet Russia", Die Welt des Islams 50/3-4 (2010), 435-76.

Kostrjukov M. A. Žuze Pantelejmon Krestovin (1870-1942 gg.): naučno-pedagogičeskaja i obščestvennaja dejatel “nost”, Kazan, Автореферат dissertacii na soiskanie učenoj stepeni kandidata istoričeskih nauk, 2010.

Kostrjukov, M. A., et M. Z. Habibullin. "Pantelejmon Krestovič Žuze : žiznennыj put' i naučnoe nasledie vidnogo predstavitelja kazanskogo vostokovedenija”, Izvestija Altajskogo Gosudarstvennogo Universiteta 4/2 (2009), 95-98.

Lammens, H. Le Berceau de l'islam. L'Arabie occidentale à la veille de l'Hégire, Rome, Sumptibus pontificii institute biblici, 1914.

Laurens, H. La Question de Palestine. 1799-1922: l'invention de la Terre Sainte, Paris, Fayard, 1999.

Lazzerini, E. "Ğadidism at the Turn of the Twentieth Century: A View from Within", Cahiers du Monde russe et soviétique 16/2 (1975), 245-77.

Müller, A. Der Islam im Morgen- und Abendland, 2 vols, Berlin, G. Grote, 1885-87.

Nöldeke, T. Die ghassânischen Fürsten aus dem Hause Gafna's, Berlin, Verlag der Königlichen Akademie der Wissenschaften, 1888.

Notice “Juze Panteleymon”, http://relstud-hist.spbu.ru/en/articles/en-zuze-pantelej mon-krestovic (site internet du projet The Study of Religion in Russia in the 18thfirst half of the 2oth century de l'Université d'État de Saint-Pétersbourg).

Notice Wikipédia en azéri, "Panteleymon Juze", https://az.wikipedia.org/wiki/Pante leymon_Juze (10 janvier 2019).

Öner, M. "Kâşgarlı Mahmud ve Panteleymon Krestoviç Juze (Al-Jawzi Bandali Saliba)" (conférence à l'Université centrale des minorités à Pékin en 2008).

Renault, M. "Lidée du communisme musulman : à propos de Mirsaid Sultan Galiev (1892-1940)", Période (revue en ligne).

Riddell, J. To See the Dawn : Baku, 1920 - First Congress of the Peoples of the East, London/ Montreal/Sydney, Pathfinder Press, 1993.

Rodinson, M. Islam et capitalisme, Paris, Seuil, 1966. 
Rodinson, M. Marxisme et monde musulman, Paris, Seuil, 1972.

Rodionov, M. "Profiles under Pressure : Orientalists in Petrograd/Leningrad, 1918-1956", in S. Conermann et M. Kemper, eds, The Heritage of Soviet Oriental Studies, London/ New York, Routledge, 2011, 29-46.

Schimmelpennick van der Oye, D. "The Imperial Roots of Soviet Orientology", in S. Conermann et M. Kemper, eds, The Heritage of Soviet Oriental Studies, London/ New York, Routledge, 2011, 29-46.

Snouck Hurgronje, C. "Une nouvelle biographie de Mohammed", Revue de l'histoire des religions 30 (1894), 48-70.

Sonn, T. "Bandali al-Jawzi's Min Tarikh al-Harakat al-Fikriyyat fi'l-Islam: The First Marxist Interpretation of Islam", International Journal of Middle East Studies 17/1 (1985), 89-107.

Sonn, T. Interpreting Islam: Bandali Jawzi's Islamic Intellectual History, New York/ Oxford, Oxford University Press, 1996.

Stavrou, T. Russian Interest in Palestine 1882-1914, Thessaloniki, Institute for Balkan Studies, 1963 .

Sultan Galiev, M. S. "Les méthodes de propagande anti-religieuse parmi les musulmans", in A. Bennigsen et C. Lemercier-Quelquejay, eds, Les Mouvements nationaux chez les musulmans de Russie. Le "sultangalievisme" au Tatarstan, Paris, Mouton \& Co, 196o, 226-38.

Swietochowski, T. Russian Azerbaijan: The Shaping of National Identity in a Muslim Community, Cambridge, Cambridge University Press, 1985.

Türkoğlu, İ. "1917 İhtilali'nden Sonra Azerbaycan'da Tarih Yazımının İnşası”, in F. Sancaktar, A. Askeroğlu Arslan, F. Ferhatoğlu, et C. Bayram, eds, Ekim 1917 Soviet İhtilalinin yüzüncü yılında türk dünyası'ndaki bağımsızlık fikri ve siyasi hareketler. Uluslararası sempozyumu 16-17 Ekim 2017, Istanbul, ŞenYıldız, 2017, 216-25.

Usmanov, M. "The Struggle for the Reestablishment of Oriental Studies in Twentieth-Century Kazan", in S. Conermann et M. Kemper, eds, The Heritage of Soviet Oriental Studies, London/New York, Routledge, 2011, 169-202.

Watt, M. Muhammad at Mecca, Oxford, Oxford University Press, 1953.

Watt, M. Muhammad at Medina, Oxford, Oxford University Press, 1956.

Werth, P. At the Margins of Orthodoxy: Mission, Governance, and Confessional Politics in Russia's Volga-Kama Region, 1827-1905, Ithaca/London, Cornell University Press, 2002. 